\title{
Second-order hyperpolarizability, Figure of merit and nonlinear optical properties of novel organic compound doped conducting polymer film
}

Hussain Ali Badran ( $\sim$ hussain_badran@yahoo.com )

University of Basrah,Education college for pure sciences https://orcid.org/0000-0002-2865-7907

Hanan A. Al-Hazam

University of Basrah

Raeed K. Alfahed

Al-Nahrain University

Khalid I. Ajeel

University of Basrah

\section{Research Article}

Keywords: Z-scan, Nonlinear refractive index, Optical limiting, Figure of merit, conducting polymer

Posted Date: February 16th, 2021

DOI: https://doi.org/10.21203/rs.3.rs-220427/v1

License: (c) (i) This work is licensed under a Creative Commons Attribution 4.0 International License.

Read Full License 


\title{
Second-order hyperpolarizability, Figure of merit and nonlinear optical properties of novel organic compound doped conducting polymer film
}

\author{
${ }^{1}$ Hussain A. Badran, ${ }^{2}$ Hanan A. Al-Hazam, ${ }^{3}$ R. K. Fakher Alfahed, ${ }^{1}$ Khalid.I.Ajeel \\ ${ }^{1}$ University of Basrah, College of Education for Pure Sciences, Department of Physics, Basrah, Iraq \\ ${ }^{2}$ University of Basrah, College of Science, Department of Chemistry Basrah, Iraq \\ ${ }^{3}$ University of Al-Nahrain, Al-Nahrain Nano- renewable Energy Research Center, Baghdad, Iraq \\ Corresponding author: hussain_badran@yahoo.com
}

\section{Abstract:}

The structural characterization of a new organic compound (3, 5-bis (4-chlorophenyl)-4,5-dihydro-1HPyrazole) was analyzed experimentally by ${ }^{1} \mathrm{HNMR}$ and FT-IR spectroscopic technique. The analysis of HOMO-LUMO and natural bond orbital are investigated to study the charge transfer interactions which is leading to the properties of nonlinear behavior. linear optical properties of anew organic compound / Poly (O- Methoxyaniline) (POMA) film was studied using Wemble and Didomenico (WD) technique to estimate the refractive index $n$ and other optical constant such as the oscillation energy $E_{0}$, the dispersion energy $E_{\mathrm{d}}$, and the lattice dielectric constant $\varepsilon_{\infty}$. Measurements of the thermally induced optical nonlinearity of novel organic compound (3, 5-bis (4-chlorophenyl)-4, 5-dihydro-1H- Pyrazole) in an organic solvent (N-methyl-2-pyrrolidone (NMP)) was studied through an excitation source (continuous wave diode laser at the wavelength of $473 \mathrm{~nm}$ ) in the case of the solution and a conducting polymer film. The Z-scan technique was used to measure the nonlinear refractive index ) to obtain the optical $n_{2}($ response of prepared material. The prepared sample illustrated negative and large $n_{2}$ values in the order of $10^{-7} \mathrm{~cm}^{2} / \mathrm{W}$ and reverse saturable absorption (RSA) with large values of the nonlinear absorption coefficient in the order of $10^{-3} \mathrm{~cm} / \mathrm{W}$. The nonlinear refractive index was determined and varied as a response to different concentrations. The determination of the figure of merit (W) and nonlinear coefficients indicate that the compound is a promising candidate for applications in the nonlinear optics field.

Keywords : Z-scan; Nonlinear refractive index; Optical limiting; Figure of merit; conducting polymer. 


\section{Introduction}

Recently, plenty of works on organic materials are investigated according to their potential applications in electronics, optoelectronics, sensor devices and shielding [1,2]. Currently, a new research area using polymeric composites emerging and gaining considerable tension. The synthesis of polymer composites, which include the nanometric organic materials is considered an integral aspect of polymer nanotechnology. Depending on the presence of the organic materials, these composites have been improved and offered especially properties various than pure polymer. There are many works performed since 1980 on the field of nonlinear optical (NLO) properties so this field became at the face of current research and gained the special interest in advanced photonic technologies according to their novel properties such as ease of processing, low cost and promising physical characteristics [3]. The third-order NLO materials have different characteristics than the second-order NLO materials due to their dimensions of the frequency space [4]. Many applications were discovered in optical fields such as dynamic holography, optical phase conjugation, all optical switching, limiting behavior... etc. Intensive works have been performed to find the third-order NLO characteristics of different materials such as inorganic materials and organic materials [5-11]. The organic materials have been known to exhibit large optical nonlinearities and third-order susceptibilities and are recognized for their intensive applications in the field of photonics, in addition to their advantages in ultrafast response [12,13]. Therefore, these materials have become a subject of intensive experimental and theoretical studies in the last few years [14-16] to measure third-order NLO characteristics of different organic materials. Most researches on organic materials have been studied in various forms (single crystals, solution, radiation materials as well as organic and biological materials in solids) [17-22]. The main aim of the current research is to prepare the high quality of a new organic compound and to investigate its optical properties. The optical parameters of films were estimated by optical properties method and both of nonlinear properties of refractive index and absorption coefficient were explored by the technique of Z-scan with $473 \mathrm{~nm}$ wavelength of used continuous-wave 
laser. The real part, the imaginary part of third-order susceptibility, $\chi^{3}$ and second-order hyperpolarizability have been characterized through Z-scan technique in the case of open and closed aperture. The optical limiting of the novel organic compound in the situation of the solution and POMA film are compared. The dependence of the threshold power value on the concentration was characterized.

\section{2- Experimental work}

\section{1- Organic Material synthesis.}

The new organic compound was synthesized as follows: A mixture of (E)-(1,3-biz(4-chlon-1phenyele) prop-2-en-1-one ( $0.03 \mathrm{~mol})$, hydrazine-hydrate $(80 \%),(0.06 \mathrm{~mol})$ and $(0.03 \mathrm{~mol})$ of sodium carbonale in $30 \mathrm{ml}$ ethanol were reflux $5 \mathrm{~h}$,The reaction is completed as indicated by TLC. The reaction mixture was sitted over crutch ice. The solid obtained was extracted as a result of filtering, thereafter the yield is washed up with water and then dried. After that the compound yield crystallizes causing by the

ethanol. The purity of the product was checked with TLC. The melting point was estimated by using Nrovector E A $300 \mathrm{~A}$ (melting point $=235^{\circ} \mathrm{C}$ ), the yield $70 \%, \mathrm{C}_{15} \mathrm{~N}_{2} \mathrm{Cl}_{2} \mathrm{H}_{2}$ compound has melting point 291.166, the CHN analysis C: 61.8719 , N: $9.6233, \mathrm{H}: 4.1543$ found C: $61.85, \mathrm{~N}: 9.619, \mathrm{H}: 4.1492$. The chemical and molecular configuration of an organic compound synthesized for the current research is shown in Figure 1. 


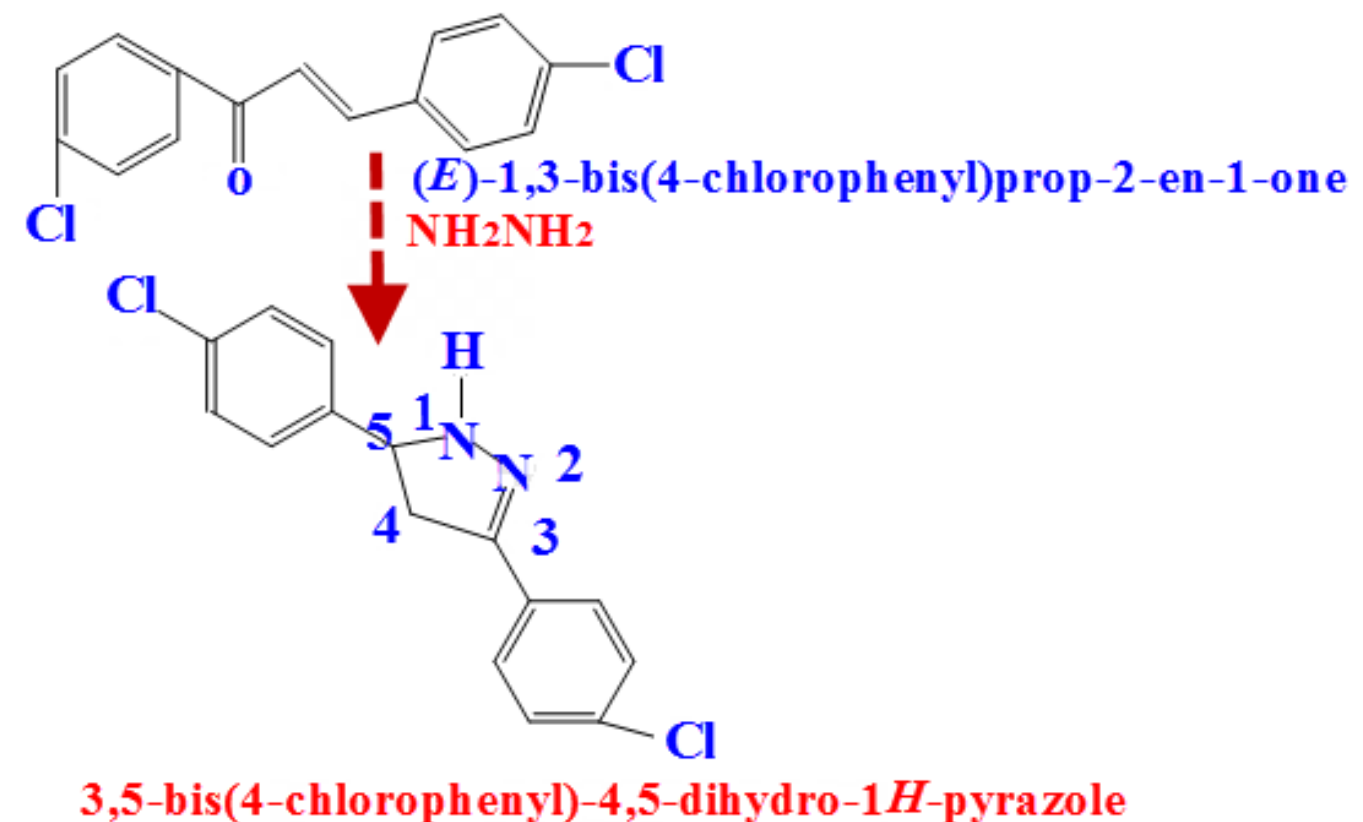

Fig.1. Schematic of new organic compound.

\section{2 - Fourier Transform Infrared (FT-IR) spectrum.}

FTIR Spectrometers are widely used in organic synthesis and polymer science since FTIR explains the mechanism of chemical reactions and the detection of unstable substances can be investigated with such instruments besides that, the FTIR technique is very suitable to provide information about the structure and chemical bonding of materials. Figure 2 shows the spectra of the new compound. It was measured as $\mathrm{KBr}$ disk for sample in the region of $400-4000 \mathrm{~cm}^{-1}$ in spectra by using denterated Dimethyl sulfoxide solvent DMSO-d6, by 300 MHz JEOL-JNM-EX results and discussion on-:IR spectra of the prepared samples, $3267.19 \mathrm{~cm}^{-1}$ for $\mathrm{NKl}$ stretching. $\mathrm{F}^{2}$ Pyrazoline ring, $3099.39 \mathrm{~cm}^{-1}$ for $\mathrm{CH}_{2}$ stretching, $3145.75 \mathrm{~cm}^{-1}$ for $\mathrm{C}-\mathrm{H}$ stretching of the aromatic ring, $1614 \mathrm{~cm}^{-1}$ for $\mathrm{C}=\mathrm{N}$ stretching of pyrazoline ring, $1562.23 \mathrm{~cm}^{-1}$ for carbon-carbon bonds $\mathrm{C}=\mathrm{C}$ stretching of the aromatic ring. It can be observed at $1251 \mathrm{~cm}^{-1}$ the C-N stretching of pyrazoline ring, around $752.19 \mathrm{~cm}^{-1}$ for $\mathrm{C}-\mathrm{Cl}$ stretching. 


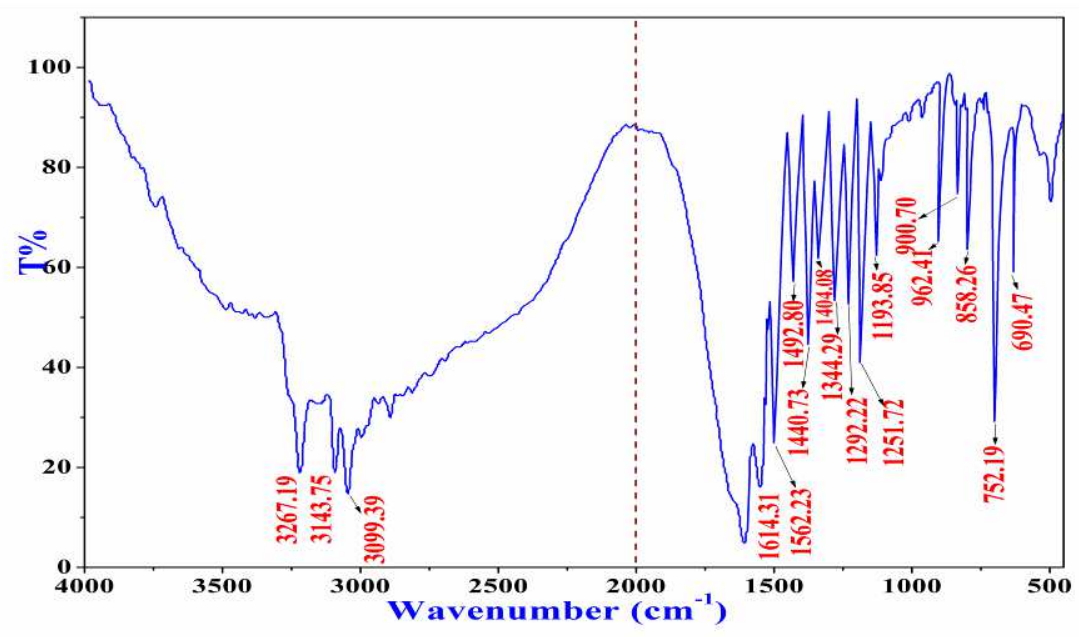

Fig.2. FT-IR spectrum of new organic compound.

\subsection{Proton NMR spectrum}

Figure 3 shows the ${ }^{1} \mathrm{HNMR}$ spectrum of the new compound which confirmed the prepared new compound. A signal was observed at $2.5 \mathrm{ppm}(1 \mathrm{~Hz}$, a) of the proton NMR spectrum which is referred to the carboxylic proton. One other sharp signal was noted at $3.5 \mathrm{ppm}(2 \mathrm{~Hz}, \mathrm{~b})$, which is specified to phenolic hydroxyl $(\mathrm{OH})$ protons. Aromatic protons and N-H of pyrazoline ring showed multiple signals with the region 7.2-8.6 ppm while $\mathrm{CH}_{2}$ of pyrazoline ring was observed at $4.1 \mathrm{ppm}$ as multiple signals. 


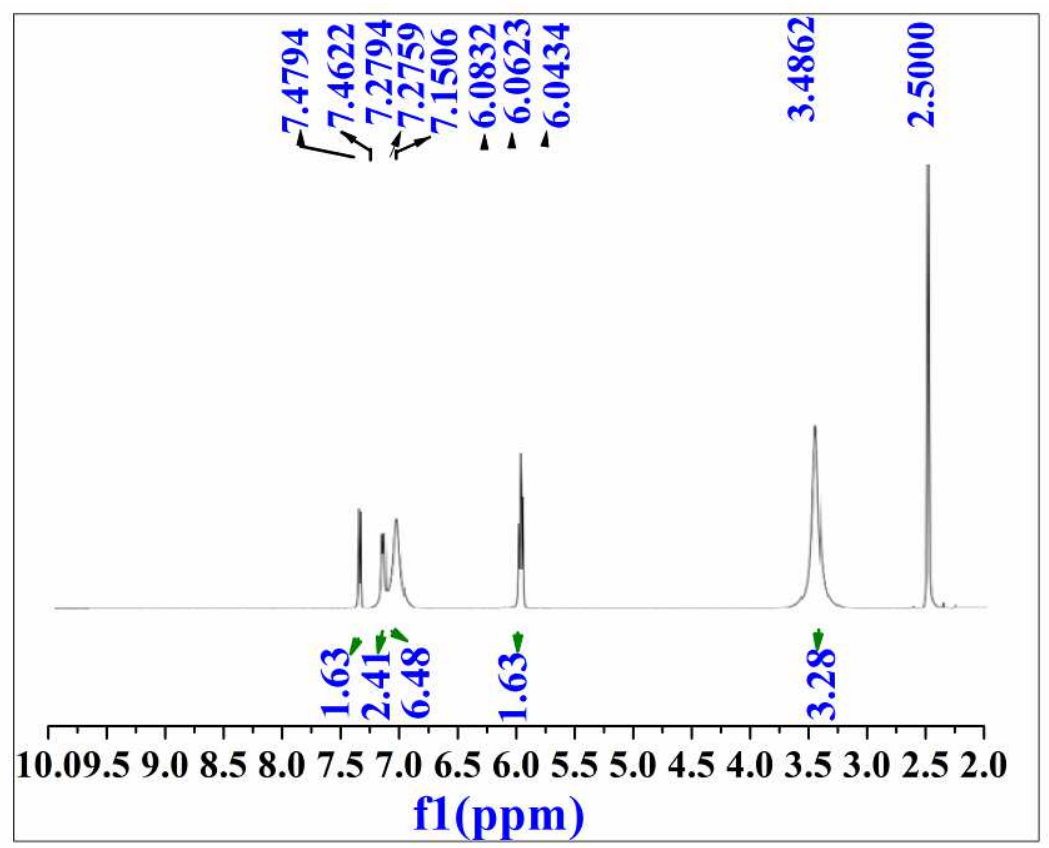

Fig. $3 .{ }^{1} \mathrm{HNMR}$ spectrum of new organic compound.

\section{2-3 ${ }^{13}$ CNMR spectrum}

${ }^{13} \mathrm{CNMR}$ data of prepared structure is shown in (Fig.4) .It was investigated based on the additive method by using MestReNova Program. The aromatic ring for prepared compound showed signals at the range $113-161 \mathrm{ppm}$ while $\mathrm{C}=\mathrm{N}$ appeared at $150.14 \mathrm{ppm}$ due to an isotropic effect. $\mathrm{CH}_{2}$ of pyrazoline ring showed signal at $150.14 \mathrm{ppm}$. The assignment of ${ }^{13} \mathrm{CNMR}$ are as follows $\mathrm{C}_{1}: 137.5, \mathrm{C}_{2}: 128.7, \mathrm{C}_{3}$, $\mathrm{C}_{4}=150.14 \mathrm{C}_{4}: 135.84, \mathrm{C}_{7}=68.52, \mathrm{C}_{10}: 150.14, \mathrm{C}_{11}: 132.39, \mathrm{C}_{12}, \mathrm{C}_{16} 127.23, \mathrm{C}_{15}, \mathrm{C}_{13}: 29.03, \mathrm{C}_{14}: 134.25$, $\mathrm{C}_{17}: 39.25$

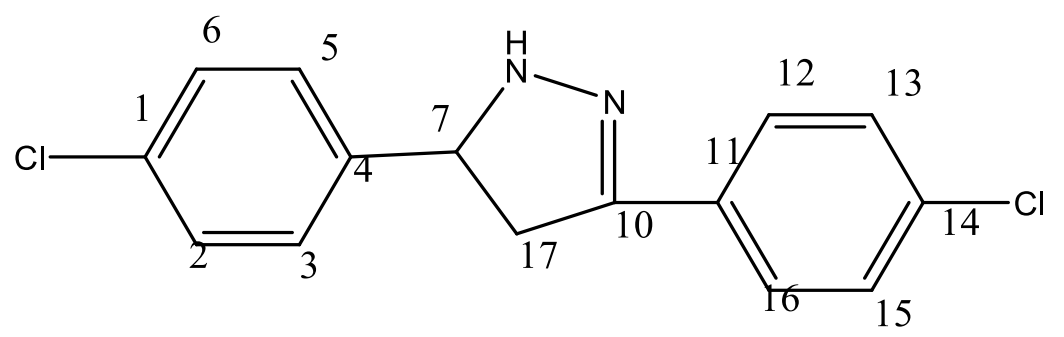

Fig.4. ${ }^{13}$ CNMR Schematic of new organic compound. 


\subsection{Quantum chemical calculations}

The calculations of the quantum chemical were performed on the super Pentium computer. The total energy and the various electronic features of the molecules such as the dipole moments, the energy of the highest occupied molecular orbital (EHOMO) and the lowest unoccupied molecular orbital (ELUMO) have been calculated using the method of density functional theory and version nine of Gaussian software program. The large value of EHOMO refers to that the molecule has the highest tendency to donate electrons. Whereas the other value of ELUMO (low value) refers to the ability to accept electrons to form stable bonds. The HOMO-LUMO energy calculations of the novel organic compound were carried out using density functional theory / B3LYP method with the 6-31G(d) basis set. Moreover, the orbital shapes of (HOMOLUMO) and the energy gap between the HOMO-LUMO which is a pivotal parameter that explain the molecular electrical transport merits are plotted in 3D as shown in Figure 5. The values of the calculated Quantum chemical such as energies, dipole moment and the frontier molecular orbital energies of the novel organic compound are given in Table 1.

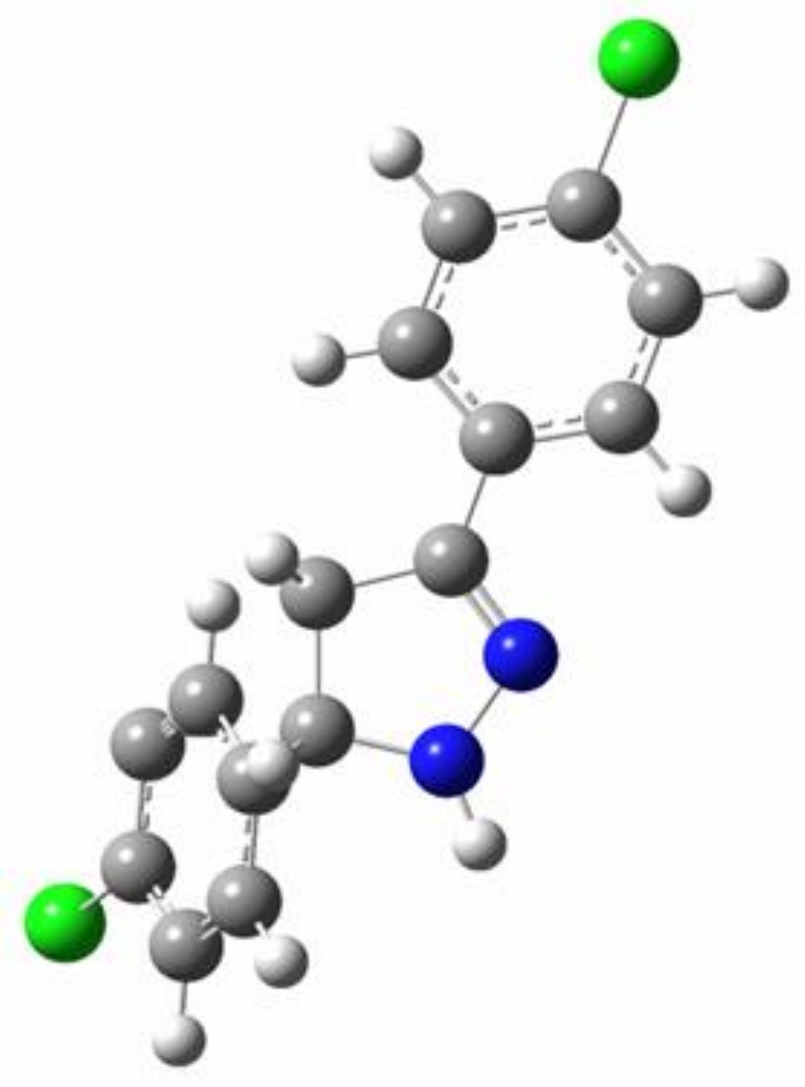



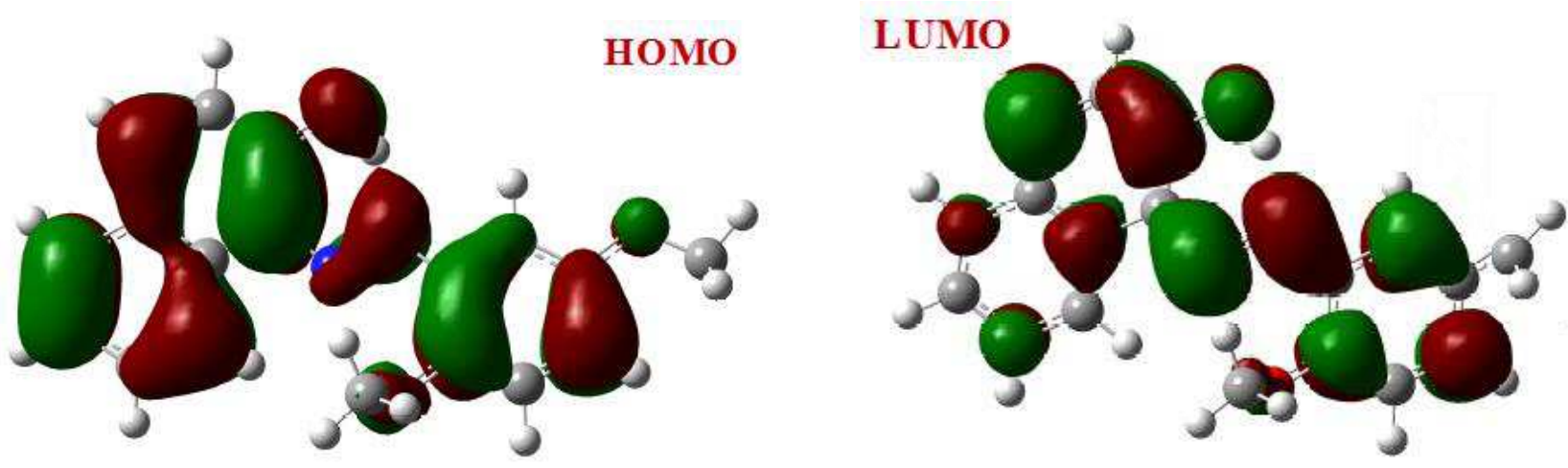

Fig.5. The optimized structure of new compound.

Table 1. Some physical properties of studied new organic compound.

\begin{tabular}{|c|c|c|c|c|c|}
\hline Molecule & $\begin{array}{c}\text { EHOMO } \\
(\mathrm{eV})\end{array}$ & $\begin{array}{c}\text { ELUMO } \\
(\mathrm{eV})\end{array}$ & $\begin{array}{c}\text { Dipole moment } \\
(\text { Debye })\end{array}$ & $\begin{array}{c}\Delta \text { E. Gap } \\
(\mathrm{eV})\end{array}$ & $\begin{array}{c}\text { Total energy } \\
(\mathrm{eV})\end{array}$ \\
\hline $\mathrm{M}$ & -8.311 & -0.425 & 2.894 & 7.886 & -3394.796 \\
\hline
\end{tabular}

By using the Lorentz-Lorentz equation [23-25], it is possible to investigate the molar refractivity $(M R)$ which is responsible for binding property and quantitative structure property relationship (QSPR) related to refractive index $(n)$, density of the molecule $(\rho)$ and molecular weight $(M W)$.

$M R=\left[\left(n^{2}-1\right)\left(n^{2}+2\right)\right] M W / \rho=1.333 \pi \alpha_{0} N_{v}^{\prime}$

where $N_{v}^{\prime}=6.023 \times 10^{23}$ molecules $\cdot \mathrm{mol}^{-1}$ is Avogadro's number and $\alpha_{\mathrm{o}}$ is the polarizability. For the novel organic compound the molar refractivity is calculated and found to be 11.41esu.

\subsection{The film Preparation and surface morphology}

The present study is examined two types of samples: solid film and solution configuration. The solid films were prepared by choosing the hard and rigid material (POMA) as a favored host. The suitable organic solvent N-methyl-2-pyrrolidone (NMP) was used to dissolve a proper amount of POMA and novel organic compound separately. However, $0.85 \mathrm{mM}$ of the new organic compound concentration in the selected solvent. Thereby, the ratio (1:1) of dissolved POMA and dye were mixed and left under stirring 
process for $2 \mathrm{~h}$. The prepared film was spun on a clean micro-slide glass substrate by the repeat-spincoating method and dried at $35{ }^{\circ} \mathrm{C}$ for $24 \mathrm{~h}$. The polymer film thickness of the Poly (O- Methoxyaniline) was measured using a sensitive digital micrometer and is found to be $9 \mu \mathrm{m}$. The solution sample of the novel organic compound was dissolved in NMP. The concentration of the dye solution is 0.5 and $0.8 \mathrm{mM}$.

The film normally exposures to a laser light beam $(4 \mathrm{~mW})$ to examine the optical quality. The results are accepted where no dust and distortion was observed in the output power of the laser beam which means that the film is homogeneous and the characteristics of optical quality are excellent. To study the surface morphologies of prepared film, optical microscopy (Novex) was setup. Figure 6a shows an image of solid film and film image by optical microscopy in a raw. The relation between the grayscale and the roughness of the film surface is detailed in Figure 6b. It can be seen from this figure the solid film is smooth and symmetric structure. The last image was analyzed using the Image $\mathbf{J}$ software to get $2 \mathrm{D}$ and 3D of the film as clear in Figure 6-c and e. Both figures proved, that film's surfaces are homogenous and uniform, out of cracks and free of pinholes. 


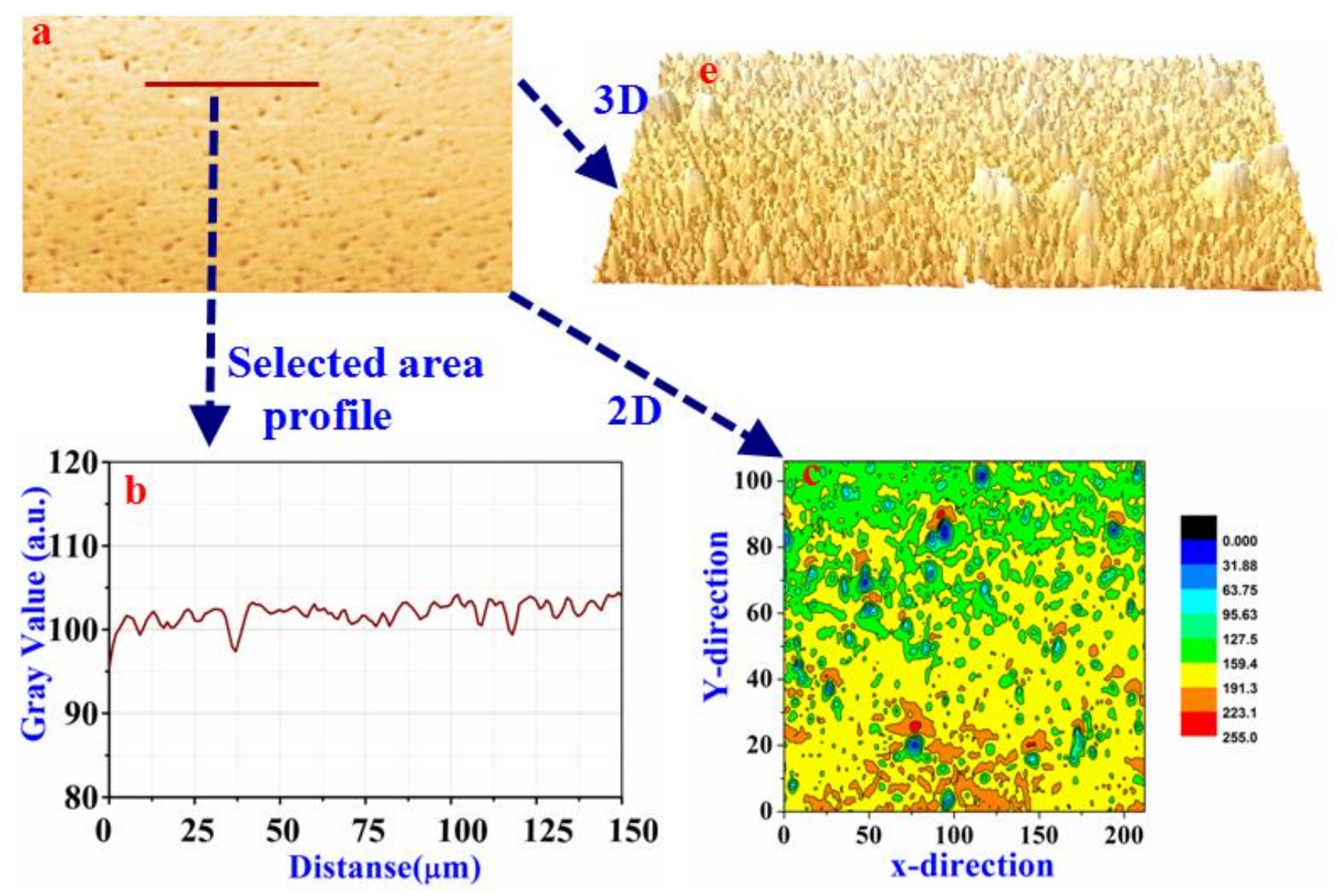

Fig.6. Photograph and Surface morphology of the POMA film.

\section{Results and Discussion}

\subsection{Linear Optical Properties Study}

To study the absorption spectrum, it is used Spectrophotometer CE-3055 with a range of 300-700 nm. Figure 7 reflects the behavior of the optical absorption spectrum for the samples. It can be observed from figure 7, that the solid sample has absorption larger than the solution sample. This is because of increasing the number of molecules per unit volume. The transmittance spectral $(\mathrm{T})$ and the reflectance spectral (R) of samples were taken at the wavelength range of 300-700 nm. 


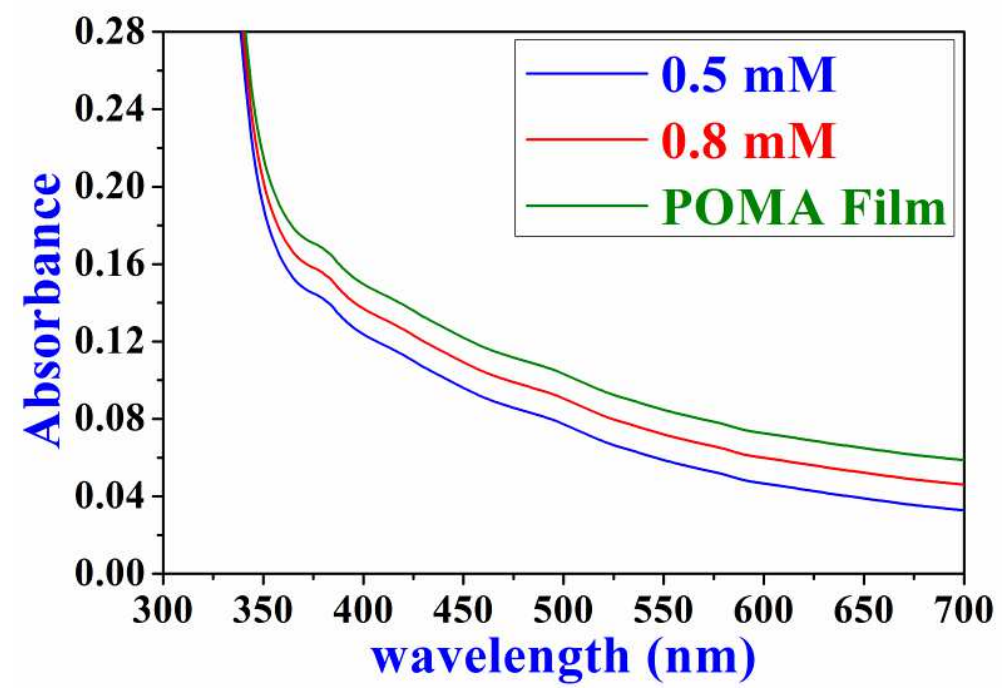

Fig.7. UV-Visible absorption spectra for POMA film and solution.

Generally, the absorption bands at $376 \mathrm{~nm}$ ( molar extinction $C=1132 \mathrm{M}^{-1} / \mathrm{cm}$ ) were noticed in the new organic compound which is attributable to the $\pi \rightarrow \pi^{*}$ transition of the aromatic rings. No d-d transitions were observed for the novel organic compound. This result may be attributed to their overlap with the $\pi \rightarrow$ $\pi^{*}$ of the $-\mathrm{CH}=\mathrm{N}-$ groups. The absence of impurities in the solid film of the organic compound-doped POMA was observed through the thin-layer chromatography (TLC) test. Figure 8 shows that the spectral's shape of $T(\lambda)$ of the POMA film appears to increase along with the optical range (400-700). Depending on the refractive index spectral at low optical frequencies which were analyzed by a single oscillator model, the constants are estimated by Wemple - Di-Domenico (WD).

To study the dispersion of refractive index (n), It used an energy parameter $E_{\mathrm{d}}$, the single oscillator energy $E_{0}$ and photon energy $E(=h v)$, as shown at the following relation [26,27]:-

$\left(n^{2}-1\right)^{-1}=\frac{E_{o}}{E_{d}}-\frac{E_{2}}{E_{o} E_{d}}$

the values of the dispersion parameters $E_{\mathrm{d}}$ and $E_{0}$ were determined by relation $\left(n^{2}-1\right)^{-1}$ versus $(h v)^{2}$ as appeared in figure 9 and it is found to be 0.402 and $2.487 \mathrm{eV}$ respectively. The high-frequency dielectric constant, $\left(\varepsilon_{\mathrm{o}}=1.319 \mathrm{eV}\right)$ has been determined by the intercept of the curve shown in figure 9 . The average 
strength of the inter-band optical transitions related to the change in the structure order of the material which is determined by the dispersion energy, $E_{\mathrm{d}}$, associated with the ionization, anion valences in addition to the coordination number for the compound and the effective oscillator energy $E_{0}$. The single oscillator equation was employed for the fit of the experimental data has the advantage to produce a physical interpretation of the determined quantities.

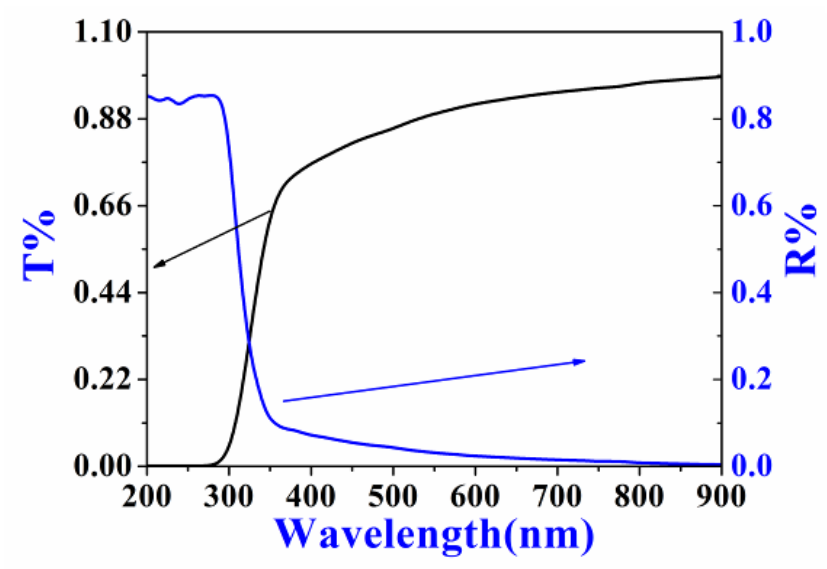

Fig. 8. $T(\lambda)$ and $R(\lambda)$ Spectral of film.

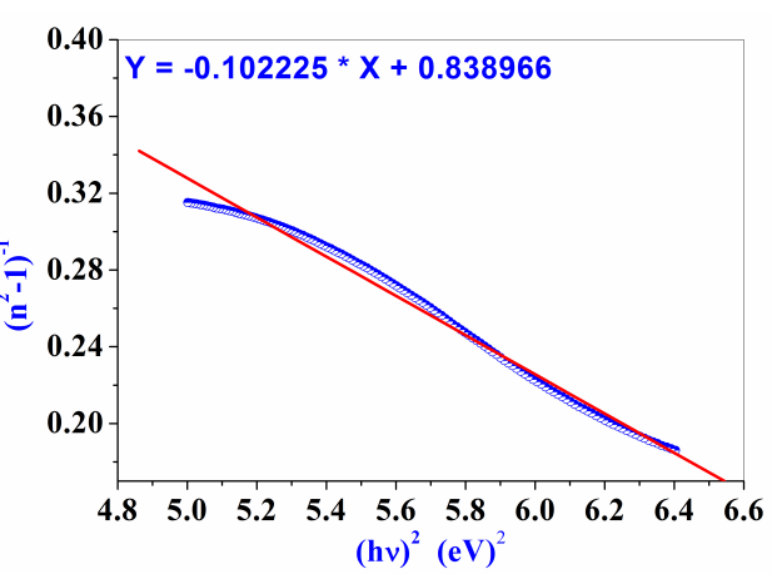

Fig. 9. Plot of $\left(n^{2}-1\right)^{-1}$ vs. (hv) $)^{2}$ of film.

The information of the quantitative overall band structure for material can be given exactly by the average gap $E_{0}$. Bringing this idea is completely different from the information is given by the energy gap value $E_{\mathrm{g}}$, which examines the optical characteristics near the band edges of the material. particularly, the localized states near the conduction or their valence band "tail states" could have a hard influence on the optical absorption which causes a decrease of the optical gap. However a resulting in small polarizability, it has a small effect on the refractive index; such tail states cause to increase the 'Urbach tail', but have a weak effect on the average gap $E_{0}$ [28]. The static refractive index, $n_{0}$, is determined from "Wemple - DiDomenico" ( WDD) dispersion parameters, $E_{0}$ and $E_{\mathrm{d}}$ by the following relation [28]:-

$n_{o}=\left(1+\frac{E_{d}}{E_{o}}\right)^{1 / 2}$

The moments of optical dispersion spectra $\mathrm{M}_{-1}$ and $\mathrm{M}_{-3}$ can be determined through the following relations [29]: 
$E_{o}^{2}=\frac{M_{-1}}{M_{-2}}$

$E_{d}^{2}=\frac{M_{-1}^{2}}{M_{-3}}$

Table2 views the calculated value, the moments $M_{-1}$ and $M_{-3}$. Most constants below were determined by using the refractive index parameters such as the average oscillator wavelength $\lambda_{\mathrm{o}}$, oscillator length strength $S_{\circ}$ as well as the long-wavelength refractive index $n_{\infty}$, of the sample. The average inter-band oscillator wavelength can be determined using, the term of Sellmeier oscillator [30].

$$
\left(n_{\infty}^{2}-1\right) /\left(n^{2}-1\right)=1-\left(\lambda_{o} / \lambda\right)^{2}
$$

where $\mathrm{n}_{\infty}$ is the refractive index at infinite wavelength $\lambda_{\mathrm{o}}$.

Table 2. The optical parameters of the organic compound doped POMA film.

\begin{tabular}{|c|c|c|c|c|c|c|c|}
\hline$E_{g}^{\text {Opt }}(\mathrm{eV})$ & $E_{o}(\mathrm{eV})$ & $E_{d}(\mathrm{eV})$ & $M_{-1}(\mathrm{eV})$ & $M_{3}(\mathrm{eV})^{-2}$ & $n_{o}$ & $\varepsilon_{o}$ & $S_{o}\left(m^{-2}\right) \times 10^{12}$ \\
\hline 3.5 & 2.528 & 0.807 & 0.319 & 0.05 & 1.48 & 2.19 & 1.967 \\
\hline
\end{tabular}

The value of $\lambda_{\mathrm{o}}$ can be found from the fitting of the relation $1 /\left(n^{2}-1\right)$ against $1 / \lambda^{2}$ as illustrated in Fig.10 and recording the value of $\lambda_{\mathrm{o}}$ equal to $439.215 \mathrm{~nm}$.

From equation ( 5 ) can be given that [31],

$n^{2}-1=\left(S_{o} \lambda_{o}^{2}\right) /\left(1-\lambda_{o}^{2} / \lambda^{2}\right)$

$S_{o}=\left(n_{\infty}^{2}-1\right) / \lambda_{o}^{2}$

The average oscillator strength $S_{0}$ (the strength of individual dipole oscillators) was computed using relation (7) as shown in table 2 , so the refractive index dispersion parameter $E_{0} / S_{0}$ for the film was determined and it is found to be $1.285 \times 10^{-12} \mathrm{eVm}^{2}$. The high-frequency dielectric constant $\varepsilon_{\infty}$ can be found from the following relation [32]:- 
$\varepsilon^{\prime}=\varepsilon_{\infty}-B \lambda^{2}$

where $\varepsilon^{\prime}$ and $\lambda$ is the real part of the dielectric constant and the wavelength respectively, B represents $e^{2} N / 4 \pi \varepsilon_{\mathrm{p}} m^{*} c^{2}$, where as $N$ represents the concentration of charge carrier , $e$ is the charge of the electron, $m^{*}$ is the electron effective mass, $\varepsilon_{P}$ is the permittivity of free space and $c$ is the light velocity. Figure 11shows the relation between $n^{2}$ and $\lambda^{2}$ for the sample. It can be seen from the figure that, the linear relation between $n^{2}$ and $\lambda^{2}$ at long wavelengths. From figure 11 can be estimated, $B$, and the value of $\varepsilon_{\infty}$ then the $N / \mathrm{m}^{*}$ ratio can be determined. The value of $\varepsilon_{\infty}$ and $\mathrm{N} / \mathrm{m} *$ is 2.3 and $5.19 \times 10^{56} \mathrm{~m}^{-3} \mathrm{~kg}^{-1}$, respectively.

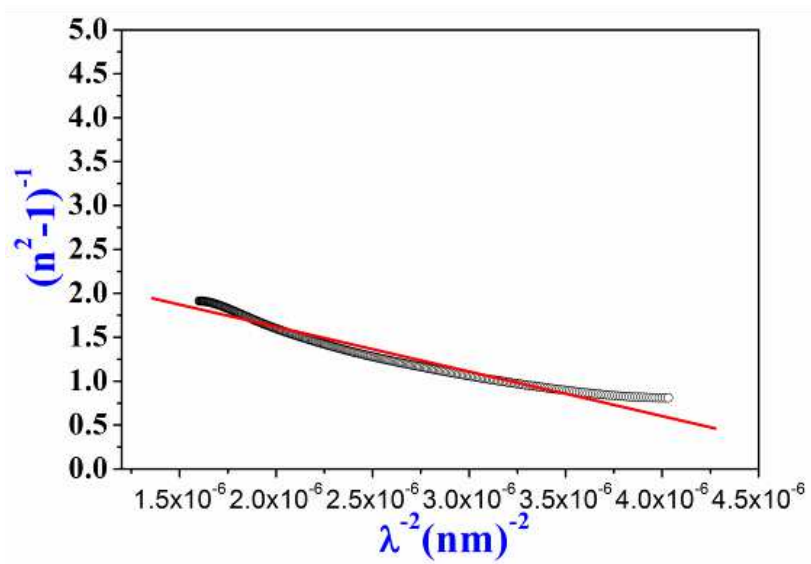

Fig.10. Plot of $\left(n^{2}-1\right)^{-1}$ vs. $\lambda^{-2}$ of film.

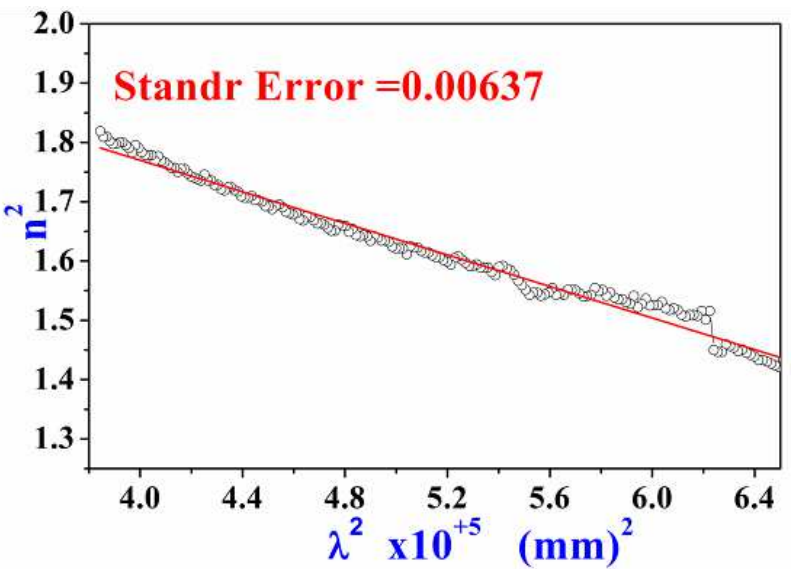

Fig.11. Plot of $n^{2}$ vs. $\lambda^{2}$ of film.

\section{2-Nonlinear properties Study}

Z-scan is a useful and easy technique that is performed to determine the nonlinear refraction and nonlinear absorption [33]. The Z-scan design depends on changing the sample position which is usually fixed on the translating stage so that it could be scanned along the laser beam direction or the scan, along $(-Z)$ and $(+Z)$ concerning the positive convex lens, then measuring the intensity's changes. As a result of the light-induced lens-like effect, the organic compound sample has the tends to collimate or defocus the 
incident beam depending on its $\mathrm{Z}$ position for the focal plane. The waist of the beam at the focus $\omega_{0}$ was estimated to be equal $19.235 \mu \mathrm{m}$ and the Rayleigh length $Z_{\mathrm{o}}$ was calculated from the following relation $[34,35]:-$

$$
Z_{\mathrm{o}}=2 \omega_{\mathrm{o}}^{2} / \lambda
$$

The compound solution and compound doped POMA film were scanned along the $Z$-axis through the focal point of the lens. During the translation method, the transmitted beam through an aperture at the farfield was taken using a digital power meter ( Field master Gs-Coherent ) covered with a narrow circular aperture. Figure 12 represents the open-aperture data of the Z-scan technique of the compound solution and compound doped POMA film. The closed-aperture Z-scan data divided by open-aperture Z-scan data for the compound solution and compound doped POMA film. The sample is shown revised saturation absorption (RSA) behavior far from the focus [36-38] and the transmission beam at the focus decreases as increases in the light intensity as shown in Figure 13. The nonlinearity is negative, this is because of the appearance of the peak followed by a valley from closed aperture z-scan (self-defocusing). It can be thought with the presence of continuous wave $(\mathrm{CW})$ pumping a major contribution causes the appeared third-order nonlinearities such as a thermal in nature sample through linear absorption which gets the energy from the focused laser beam. This energy causes a change in heating thereafter a temperature gradient. Because of the thermal lens effect, the distortion in the phase of the propagating beam occurred. $\Delta T_{p-v}$ can be measured as the difference between the maximum normalized transmittance and minimum and the relation between $\Delta T_{p-v}$ quantity and $\Delta \Phi_{o}[39]$ is:-

$$
\Delta T_{p-v}=0.406(1-S)^{0.25}\left|\Delta \Phi_{o}\right|
$$




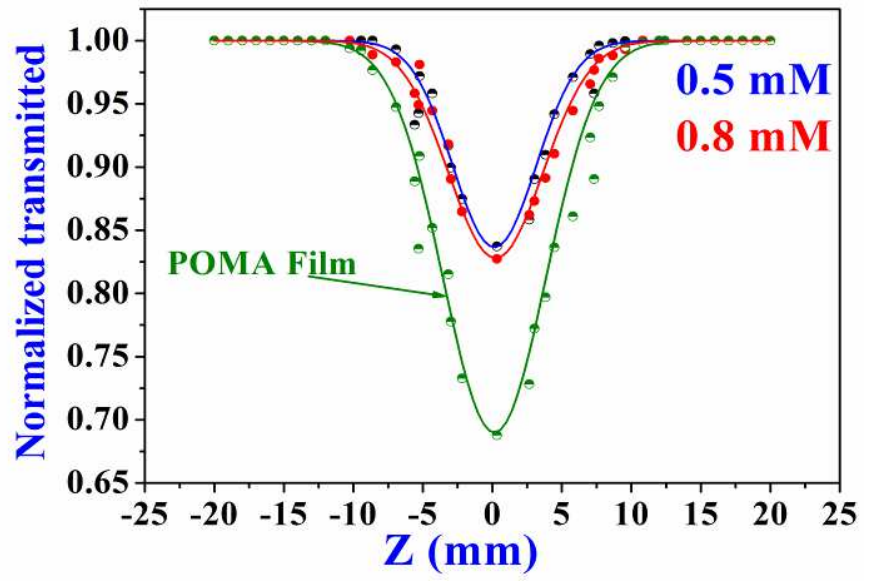

Fig.12. Open Aperture data.

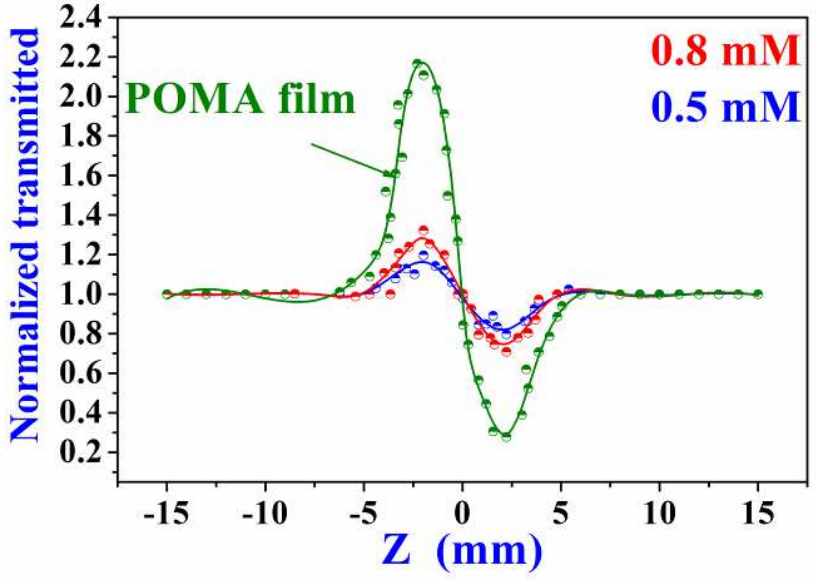

Fig. 13. Pure experemental data.

where $\mathrm{S}$ is defined as the linear transmittance of aperture $\left(\mathrm{S}=1-\exp \left(-2 \mathrm{r}_{\mathrm{a}}{ }^{2} / w_{\mathrm{a}}{ }^{2}\right)[40]\right), r_{\mathrm{a}}$ is the radius of the aperture $\left(r_{\mathrm{a}}=2.5 \mathrm{~mm}\right)$ and $w_{\mathrm{a}}$ is the radius of the beam at the aperture and found to be $\omega_{a}=2.45 \mathrm{~mm}$.

The nonlinear refractive index $\left(n_{2}\right)$ can be determined from the following relation [41,42]:-

$n_{2}=\frac{\Delta \Phi_{o} \lambda}{2 \pi L_{e f f} I_{o}}$

where $\lambda$ is the laser beam wavelength, $I_{0}$ is the intensity of the laser beam at the focal point $(\mathrm{Z}=0)$, $L_{\text {eff }}=(1-\exp (-\alpha L)) / \alpha[43]$ represents the film effective thickness, while $\alpha$ is represent the linear absorption coefficient $\left(\alpha=2.303 a / t^{\prime}\right)[44,45] . a$ and $t^{\prime}$ are the absorbance and the sample thickness respectively. The nonlinear absorption coefficient $\beta$ can be determined from the open aperture (OA) Zscan data as shown in the following relation [46- 48]:-

$\beta=\frac{2 \sqrt{2} \Delta T}{I_{\mathrm{o}} L_{\text {eff }}}$

where $\Delta T$ is represent the difference transmission of one-valley. For a laser input power of $12 \mathrm{~mW}$ $\left(I_{\mathrm{o}}=1.322 \mathrm{~kW} / \mathrm{cm}^{2}\right)$. With the assistance of figures 12 and figure 13 the nonlinear absorption coefficient $\beta$ and nonlinear refractive index $n_{2}$ can be determined and are shown in Table 3. 
The third-order susceptibility $\chi^{(3)}$ of the nonlinear behavior was determined with the Z-scan technique in a single beam configuration. By knowing the experimental values of $n_{2}$ and $\beta$, one can estimate the real part and imaginary part of the third-order susceptibility $\chi^{(3)}$ of the nonlinear behavior for novel organic compound solutions and organic compound / (POMA) film according to the equations below [49-51]:-

$\operatorname{Re} \chi^{(3)}(e s u)=\frac{10^{-4} \varepsilon_{0}^{\prime} c^{2} n_{0}^{2} n_{2}}{\pi}$

$\operatorname{Im} \chi^{(3)}(e s u)=\frac{10^{-2} \varepsilon_{0}^{\prime} c^{2} n_{0}^{2} \lambda \beta}{4 \pi^{2}}$

where $\varepsilon_{0}^{\prime}$ is the vacuum permittivity and $c$ is the light velocity in vacuum.

The values of the third-order nonlinear susceptibility $\chi^{(3)}$ for the solution samples and polymer film are determined using the relation $\left|\chi^{3}\right|=\left[\left(\operatorname{Re}\left(\chi^{3}\right)^{2}+\left(\operatorname{Im}\left(\chi^{3}\right)^{2}\right]^{\frac{1}{2}}\right.\right.$, as shown in Table 3 .

The second-order hyperpolarizability, $\gamma$ of the 3, 5-bis (4-chlorophenyl) -4,5-dihydro- $1 H$-Pyrazole compound is linked to the third-order susceptibility [52] through the following relation:-

$\gamma=\frac{\chi^{3}}{\left[\frac{1}{3}\left(n_{\mathrm{o}}^{2}+2\right)\right]^{4} \times N}$

where $\mathrm{N}$ is the molecular number density in $\mathrm{cm}^{-3}$. The Lorentz field-factor or the local field correction factor is given by $\left(\left(n_{\mathrm{o}}^{2}+2\right) / 3\right)$ where $n_{\mathrm{o}}$ is the background linear refractive index. The experimental values of $n_{2}, \beta$, real part and imaginary part of the third-order nonlinear optical susceptibility $\chi^{(3)}$ and $\gamma$ are shown in Table 3. The calculated $n_{2}$ value of new organic compound doped conducting POMA in case of the solid film large than in the case of a solution, this result referred to three reasons, firstly, in the case of organic compound film, the absorption coefficient $(\alpha)$ becomes large compared with it is a solution case. secondly, in the solution case, the heat dissipation becomes fast in comparison with a solid film and thirdly, the attributed to the Anderson localization of photons [53]. Therefore, the nonlinearity property of 
optical materials increasing as a response to strong electromagnetic field localization inside the solid film due to a strong scattering system, which is happening as the scattering mean free path of photons which becomes low in comparison with a solution case. For actual use in ultrafast optical switching, communication and storage devices many studied have been taken into account to examine the effectiveness of nonlinear organic compounds. The figure of merit $W$ has to be satisfied for $2 \pi$ phase shift in order to estimate its application in such devices [54]:

$W=\frac{\Delta_{\max }}{\alpha \lambda}>1$

Under $473 \mathrm{~nm}$ excitation, $W>1$ which indicates that, the nonlinear optical properties of novel organic compound doped conducting POMA are sufficient for applications in all optical switching technology. This high value of figure of merit (Table 3) makes novel organic compound doped conducting POMA promising for use in all-optical switching devices.

Table 3: Nonlinear optical coefficients, third-order susceptibility, second-order hyperpolarizability and figure of merit of new compound solution and POMA film.

\begin{tabular}{|c|c|c|c|c|c|c|c|}
\hline Sample & $\begin{array}{c}\text { Concentration } \\
(\mathrm{mM})\end{array}$ & $\begin{array}{c}n_{2} \times 10^{-7} \\
\left(\mathrm{~cm}^{2} / W\right)\end{array}$ & $\begin{array}{c}\beta \times 10^{-3} \\
(\mathrm{~cm} / W)\end{array}$ & $\begin{array}{c}\operatorname{Re} \chi^{(3)} \times 10^{-6} \\
(\mathrm{esu})\end{array}$ & $\begin{array}{c}\mid \chi^{(3)} \times 10^{-6} \\
(\mathrm{esu})\end{array}$ & $\begin{array}{c}\gamma \times 10^{-12} \\
(\mathrm{esu})\end{array}$ & $\begin{array}{c}\text { Figure } \\
\text { of } \\
\text { merit }(W)\end{array}$ \\
\hline $\begin{array}{c}\text { Compound } \\
\text { solution }\end{array}$ & 0.5 & -0.78 & 3.84 & 3.36 & 3.43 & 0.41 & 1.10 \\
\hline $\begin{array}{c}\text { Compound } \\
\text { solution }\end{array}$ & 0.8 & -10.60 & 4.14 & 4.63 & 4.69 & 0.68 & 1.29 \\
\hline POMA film & 0.85 & -134.09 & 192.42 & 744.86 & 746.24 & 10.28 & 1.304 \\
\hline
\end{tabular}

Finally, the thermally induced on-axis nonlinear refractive index of the novel organic compound in a N-methyl-2-pyrrolidone (NMP) solventand new organic compound / (POMA) film can be estimated 
from the nonlinear refractive index value obtained from the Z-scan trace using the following equation [55]:-

$$
n_{2}=\frac{d n}{d T} \cdot \frac{\alpha \omega_{0}^{2}}{4 k_{t h}}
$$

where $d n / d T\left(\mathrm{~K}^{-1}\right)$ is the change of the refractive index to the temperature or the thermo-optic coefficient of novel compound and $k_{t h}$ is the thermal conductivity of the N-methyl-2-pyrrolidone (NMP )solvent. Finally, by using Eq.(17) with the thermal conductivity, $k_{t h},\left(=0.187 \mathrm{~W} \cdot \mathrm{m}^{-1} \cdot \mathrm{K}^{-1}\right)$, the thermo-optic coefficient $d n / d T$ of novel organic compound in NMP solvent $(0.5$ and $0.8 \mathrm{mM})$ and new organic compound / Poly (O- Methoxyaniline) (POMA)film has been found to be $-5.11 \times 10^{-5} \mathrm{~K}^{-1},-5.98 \times 10^{-5} \mathrm{~K}^{-1}$, and $-6.03 \times 10^{-5} \mathrm{~K}^{-1}$ respectively.

\section{Optical limiting behavior}

The properties of the optical limiting behavior of the novel organic compound solutions and their polymeric film were studied using solid-state laser type SDL with a wavelength of $473 \mathrm{~nm}$. Figure 14 represents the setup of experimental studies on the properties of optical limiting behavior. When the laser beam initially passes through the attenuator beam (A), focused by a lens with a focal length of $+5 \mathrm{~cm}$. A quartz cell thickness of $0.1 \mathrm{~cm}$ was utilized to contain the organic compound solution. But in the case of organic compound / Poly (O- Methoxyaniline) (POMA) film, the quartz cell will be replaced by the POMA thin film. The sample was placed behind the focal length. The beam transmitted from the sample

will be measured by the photodetector linked with the power meter. The limiting behavior was studied by adjusting the laser input to observe the laser output power. 


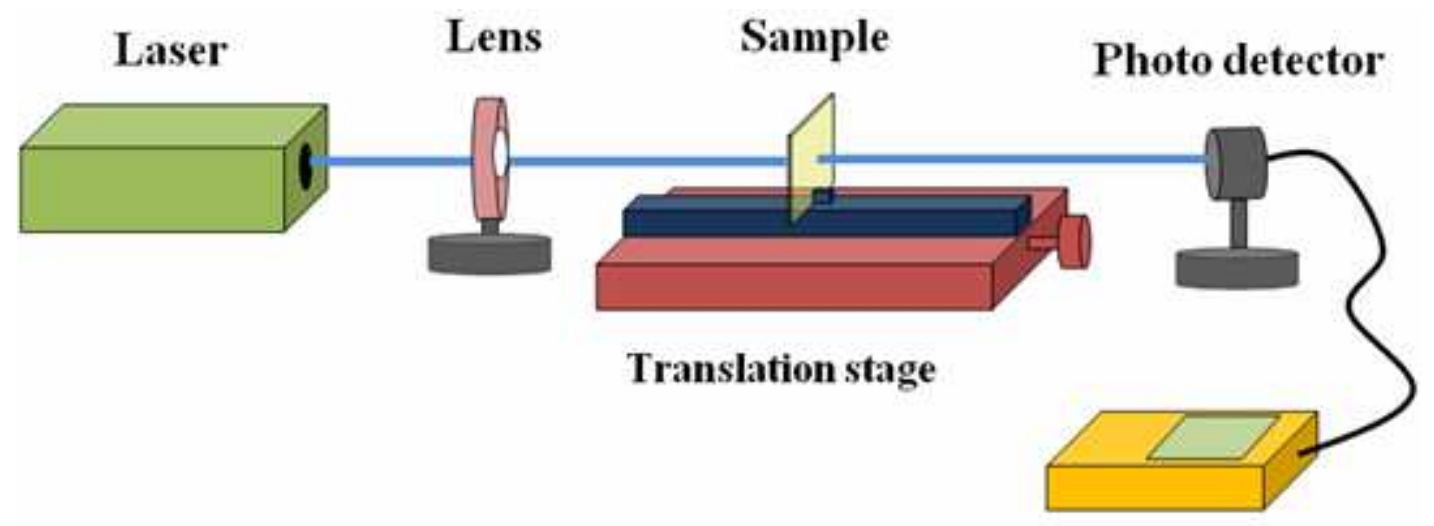

Digital power meter

Fig.14. Optical limiting experimental setup.

There is an important parameter to evaluate the optical limiting property of an organic compound called the limiting threshold. The limiting threshold is defined as the input power at which the transmittance equals 50\% of the linear transmittance [56]. The threshold value is depending on the concentration of the sample. The optical limiting behavior of organic compound solution was experimentally studied with concentrations of $0.5 \mathrm{mM}$ and $0.8 \mathrm{mM}$, and $0.85 \mathrm{mM}$ concentration for organic compound doped POMA film. Fig. 15 shows the experimental results of the limiting behavior of the organic compound solution and organic compound doped POMA film for three concentrations respectively.

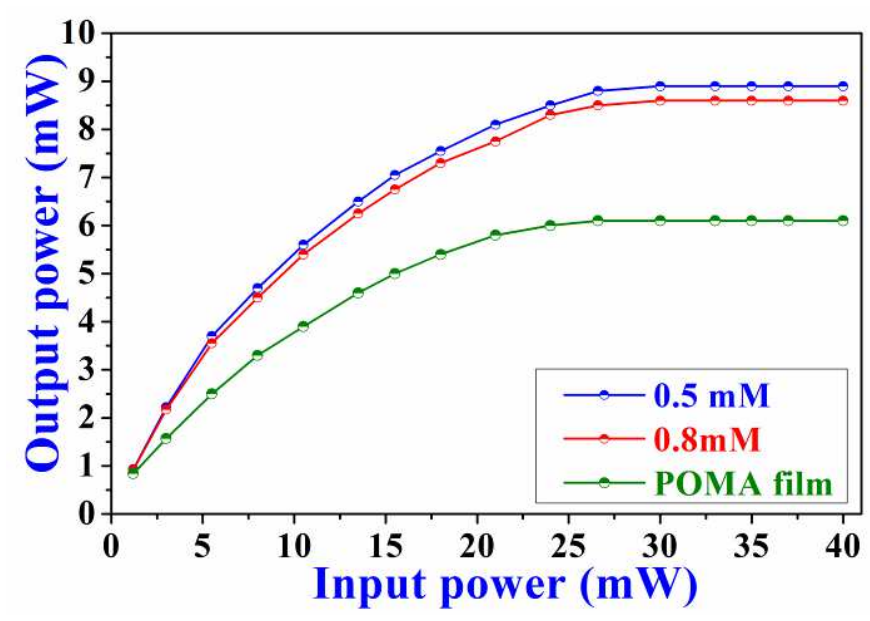

Fig.15. Optical limiting for organic compound solution and POMA film.

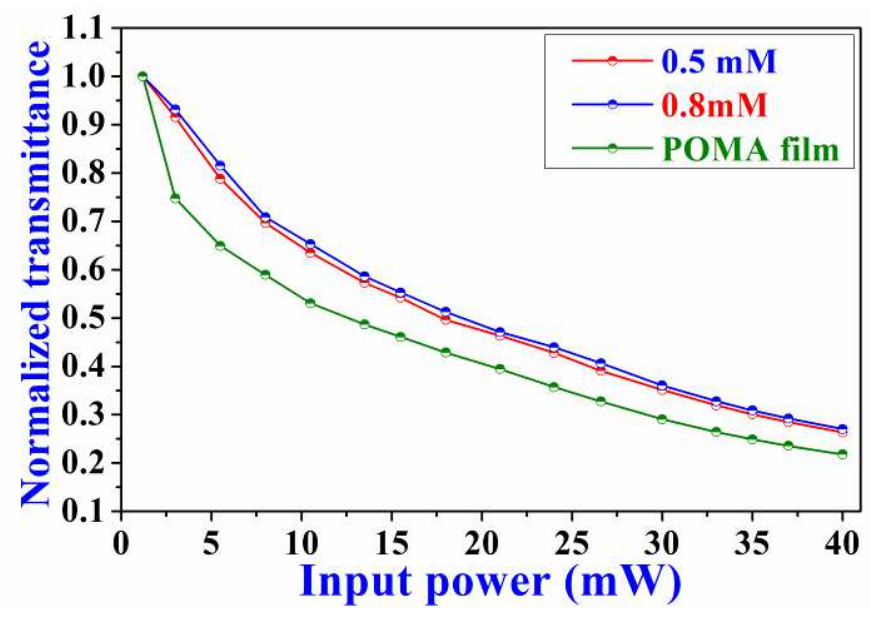

Fig.16. Normalized transmittances for organic compound solution and POMA film. 
At the low input power, the output will be varied linearly, as shown in Fig. 15. Moreover, the increase in input laser power up to the threshold of the limiter will be observed the output which begins to shift from the linear relationship. The saturation state of output power was reached while stilling an increase in the input power. Also, the same behavior was recorded with organic compound POMA film as shown in Fig. 15. To calculate the limiting threshold values of organic compound solution and organic compound POMA film, the normalized transmittances data as a function of the input power of the new compound solution and compound doped POMA film are drawn (see fig.16). Fig.16 shows the limiting threshold value which is an input power value to reduce the transmittance up to it is half value and decreases with increasing the concentration, these values are shown in Table 4.

Table 4: Threshold power and saturation power of new organic compound solution and organic compound doped POMA film.

\begin{tabular}{|c|c|c|c|c|}
\hline Sample & $\begin{array}{c}\text { Concentration } \\
(\mathrm{mM})\end{array}$ & $\alpha\left(\mathrm{cm}^{-1}\right)$ & $\begin{array}{c}\text { Threshold power } \\
(\mathrm{mW})\end{array}$ & $\begin{array}{c}\text { Saturation power } \\
(\mathrm{mW})\end{array}$ \\
\hline Compound solution & 0.5 & 1.98 & 18.83 & 8.82 \\
\hline Compound solution & 0.8 & 2.29 & 17.67 & 8.49 \\
\hline POMA film & 0.85 & 287.36 & 12.44 & 6.10 \\
\hline
\end{tabular}

The sample with a low concentration $(0.5 \mathrm{mM})$ has fewer molecules per unit volume compared to the high concentration sample. Hence the low concentration sample will have few interacting molecules during the nonlinear absorption processes. Furthermore, the optical limiting response of the prepared samples with a high concentration has a higher value compared with a low concentration. Each organic compound sample in this study gives an optical limiting behavior. Many mechanisms explain the optical limiting behavior such as nonlinear scattering [57-60], nonlinear absorption (two-photon absorption (TPA) and RSA [6164], and nonlinear refraction (electronics or thermal effects) $[65,66]$. In the present study CW laser sources are used, therefore, the origin of nonlinearity is thermal in nature. 


\section{Conclusion}

The structural, surface morphology and nonlinear optical properties of the novel organic compound are characterized by ${ }^{1} \mathrm{HNMR},{ }^{13} \mathrm{CNMR}$ spectrum, FT-IR spectroscopic technique and UV-Vis spectroscopic technique. The HOMO and LUMO analysis confirm the intramolecular charge-transfer interactions, suggest the better nonlinear optical response of the molecule. The determination of first and second-order hyperpolarizability value refers that the molecule of material has a nonlinear optical response. The nonlinear absorption and nonlinear refractive index of a new organic compound solution and organic compound doped Poly (O- Methoxyaniline) (POMA) film were studied using M. Sheik-Bahai technique (Z-scan technique) [67] with the continuous-wave laser operating at $473 \mathrm{~nm}$ wavelength. The Zscan experiment result confirms the novel organic compound exhibits negative $n_{2}$ and positive $\beta$. The negative mark of the third-order $n_{2}$ means that the novel organic compound (3,5-bis (4-chlorophenyl)4,5-dihydro- $1 H$-Pyrazole) behaves as a self-defocusing optical nonlinearity. The real $\chi^{3}$, imaginary part of $\chi^{3}$, second-order hyperpolarizability and figure of merit are also estimated experimentally. The magnitude of $\beta(\mathrm{cm} / \mathrm{W})$ and $n_{2}(\mathrm{~cm} / \mathrm{W})$ are of the order of $10^{-3}$ and $10^{-7}$ respectively. The third-order susceptibility $\chi^{3}$ and the second-order hyperpolarizability, $\gamma$ are in the order of $10^{-6} e s u$ and $10^{-12} e s u$, respectively. The optical limiting properties of the new organic compound solution and organic compound doped conducting polymer were studied through the same continuous-wave laser. The influences of the organic compound solution with different concentrations and the organic compound doped Poly (OMethoxyaniline) (POMA) film on the optical limiting characterizations are tested. The threshold power (limiting threshold) of the new organic compound was decreased according to the increase in the concentration which is a behavior property of the optical limiting. It is also indicated that the limiting threshold power is less at the organic compound sample which has a large value of linear absorption coefficient $\alpha$. Moreover, the value of threshold power was less in the case of the organic compound 
doped Poly (O- Methoxyaniline) (POMA) film compared with the organic compound solution. These results indicate that the present samples are promising candidates for applications in the nonlinear optical field.

\section{References}

[1] R. K. Fakher Alfahed, K. K. Mohammad, M. S. Majeed, H. A. Badran, K. M. Ali, B. Y. Kadem, Preparation, morphological, and mechanical characterization of titanium dioxide (TiO2)/ polyvinyl alcohol (PVA) composite for gamma-rays radiation shielding, IOP Conf. Series: Journal of Physics: Conf. Series 1279 (2019) 012019 (10 pages)

[2] F. A. Al-Saymari, H. A. Badran, A. Y. Al-Ahmad, C. A. Emshary, Time dependent diffraction ring patterns in bromothymol blue dye doped PMMA film under irradiation with continuous wave green laser light, Indian J. Phys. 87(2013) 1153-6.

[3] H. Ali Badran, Thermal lens and all optical switching of new organometallic compound doped polyacrylamide gel, Results in Physics 4 (2014) 69-72.

[4] A.Y. AL-Ahmad, M.F. AL-Mudhaffer, H.A. Badran, C.A. Emshary, Nonlinear optical and thermal properties of BCP:PMMA films determined by thermal self-diffraction. Opt. Laser Technol.54 (2013) 72-78.

[5] C. Gayathri, A. Ramalingam, Z-scan determination of the third-order optical nonlinearities of an azo dye using diode-pumped Nd:Yag laser, Optik 119 (2008) 409-414.

[6] M. Zhang, Z .M. Su, Y. Q. Qiu, X. M. Pan, I. Zhao,Y. Zhao,Y. Liao and C. S. Qin, Calculated UVVisible spectra and third-order nonlinear optical properties of heteroaromatic derivatives of stilbene inserted with 1,3-squaraine, Synth. Met. 137 (2003)1525-1526.

[7] S. S.Chu, F. M. Li, H. Z. Tao, H.Yang, S. F.Wang, C. G. Lin, X. J. Zhao, Q. H.Gong, SbS3 enhanced ultrafast third-order optical nonlinearities of Ge-S chalcogenide glasses at $820 \mathrm{~nm}$, Opt. Mater, 31 
(2008) 193-195.

[8] Z. Y. Tian, W. T. Huang, D. B. Xiao, S. Q. Wang, Y. S. Wu, Q. H. Gong, W. S. Yang, J. N. Yao, Enhanced and size-tunable third-order nonlinearity of nanoparticles from an azo metal chelate. Chem. Phys Lett. 391(2004) 283-287.

[9] J. B. Han, H. J. Zhou, Q. Q. Wang, Conductivity and optical nonlinearity of $\mathrm{Sb}$ doped $\mathrm{SnO}_{2}$ films Mater. Lett. 60 (2006) 252-254.

[10] X. B. Chen, J. J. Zhang, H. B. Zhan, Z. H. Jiang, G .Shi, Y.B Li, Y. L. Song, Preparation and nonlinear optical studies of a novel thermal stable polymer containing azo chromophores in the side chain, Dyes Pigments 77 (2008) 223-228.

[11] H.Y. Xu, S.C.Yin, W.J. Zhu, Y.L. Song, B.Z.Tang, Synthesis and optical properties of three novel Functional polyurethanes bearing nonlinear optical chromophoric pendants with different $\pi$ electron conjugation bridge structure, Polymer 47 (2006) 6986-6992.

[12] J. J. Rodrigues Jr, C. H. T. P.Silva, S. C.Zilio, L. Misoguti, C. R. Mendonca, Femtosecond Z-scan measurements of nonlinear refraction in amino acid solutions, Opt. Mater. 20 (2002) 153-157.

[13] H. A. Badran, K. Abd. AL Aladil, H. G. Lazim, A.Y. Al- Ahmad, Thermal blooming and photoluminescence characterizations of sol-gel CdO-SiO 2 with different nanocomposite, J Mater Sci: Mater Electron 27 (2016) 2212-2220.

[14] R. D. Present, Chapman-Enskog Method in Chemical Kinetics, J. Chem. Phys. 48 (1968) 4875.

[15] J. Ross, P. Mazur, Some Deductions from a Formal Statistical Mechanical Theory of Chemical Kinetics, J. Chem. Phys. 35 (1961) 19.

[16] B. Shizgal, M. Karplus, Nonequilibrium Contribution to the Rate of Reaction. III. Isothermal Multicomponent Systems, J. Chem. Phys. 54 (1971) 4357.

[17] G. M. Cartes, M. K.Thakar, Y. J. Chen, J. V. Hryniewicz, Time and wavelength resolved nonlinear optical spectroscopy of a polydiacetylene in the solid state using picosecond dye laser pulses, Appl. 
Phys. Lett. 47 (1985) 457-459.

[18] Ch. Bosshard, K. Sutter, R. Gunter, G. Chapuis, Linear- and nonlinear-optical properties of 2cyclooctylamino-5-nitropyridine, J. Opt. Soc. Am. B 6 (1989) 721-725.

[19] G. S. He, C. Xu, P. N. Prasad, B. A. Reinhardt, J. C. Bhatt, R. McKellar, A. G. Dillard, Two-photon absorption and optical-limiting properties of novel organic compounds, Opt. Lett.20 (1995) 435-437.

[20] T. M. Salman, A. Y. AL-Ahmad, H. A. Badran, C. A. Emshary, Diffused transmission of laser beam and image processing tools for alpha-particle track-etch dosimetry in PM-355 SSNTDs, Phys. Scr. 90 (2015) 085302-9

[21] T. A. Shankoff, Recording Holograms in Luminescent Materials, Appl. Opt. 8(1969) 2282-2284.

[22] S. C. Yang, Q. M. Qian, L. P. Zhang, P. H. Qiu, Z. J. Wang, Measurements for the nonlinear refractive index of a new kind of polymer material doped with chlorophyll using nanosecond laser pulses, Opt. Lett. 16 (1991) 548-550.

[23] J. A. Padron, R. Carrasco, R. F. Pellon, Molecular descriptor based on a molar refractivity partition using Randic-type graph-theoretical invariant. J. of Pharmacy Pharmaceutical (2002) 258-265.

[24] R. P.Verma, C. Hansch, A comparison between two polarizability parameters in chemical-biological interactions, Bioorganic \& Medicinal Chemistry, 13 (2005) 2355-2372.

[25] R. P. Verma, A. Kurup, C. Hansch, On the role of polarizability in QSAR, Bioorganic \& Medicinal Chemistry, 13 (2005) 237-255.

[26 ] H. A. Badran, A. Y. Taha , A. F. Abdulkader, C. A.Emshary, Preparation and study of the electrical and optical properties of a new azo dye (4-Acetaminophenol - [2-(4-Azo)]-4- Amino Dipheyl Sulfone), J. of Ovonic Research. 8 (2012) 161-170.

[27] S.H. wimple, M. Di Domenico, Optical Dispersion and the Structure of Solids, Phys. Rev. Lett. 23, (1969) 1156-1160.

[28] H. A. Badran, A. Al-Maliki, R. K. Fakher Alfahed, B. Ali Saeed, A. Y. Al-Ahmad, F. A. Al- 
Saymari, R. S. Elias, Synthesis, surface profile, nonlinear reflective index and photophysical properties of curcumin compound, J Mater Sci: Mater Electron 29 (2018) 10890-10903.

[29] H. A. Badran, H. F. Hussain, K. I. Ajeel, Nonlinear characterization of conducting polymer and electrical study for application as solar cells and its antibacterial activity, Optik ,127 (2016) 53015309.

[30] B. Kadem, R.F. Alfahed, A.S. Al-Asadi, H.A. Badran, Morphological, structural, optical and photovoltaic cell of copolymer P3HT: ICBA and P3HT: PCBM, Optik 204 (2020) 164153.

[31] H.S. Shaaker, W.A.Hussain, H. A. Badran, Determination of the optical constants and optical limiting of doped malachite green thin films by the spray method. Adv. Appl. Sci. Res. 3 (2012) 2940-2946.

[32] H. A. Badran, A.A. Al-Fregi, Synthesis and study of nonlinear optical properties of a new azo dye by Z-Scan technique. Int. J. of Semiconductor Science \&Technology (IJSST) 2 (2012) 26-36.

[33] H. A. Badran, Thermal properties of a new dye compound measured by thermal lens effect and Zscan technique, Appl. Phys. B 119 (2015) 319-326.

[34] H.A. Al-Hazam, R.K. Fakher Alfahed, A. Imran, H.A. Badran, H.S. Shaker, A.A. Alsalihi, K.I. Ajeel, Preparation and optoelectronic studies of the organic compound [2-(2,3-dimethyl phenylamino)- $N$ Phenyl benzamide doped(PMMA)]. J. Mater. Sci.: Mater. Electron. 30 (2019) 10284-10292.

[35] K. Abd AL-Adel, H. A. Badran, Nonlinear optical properties and diffraction ring patterns of benzo congo red, European Journal of Applied Engineering and Scientific Research, 1(2012) 66-72.

[36] M. T. Obeed, R. Ch. Abul-Hail, H. A. Badran, gamma irradiation effect on the nonlinear refractive index and optical limiting behavior of pyronine y dye solution, J. of Basrah Researches (Sciences) 46 (2020) 49-56.

[37] H. A. Badran, Investigation of the nonlinear optical response of 3-(dimethylamino)-7-aminophenothiazin-5-ium chloride dye. IOSR J. Appl. Phys. 1(2012) 33-37.

[38] H.A. Badran, A.A. Jari, Measurements of third-order susceptibility of 3-[[(4-methyl-1-piperazinyl) 
imino]-methyl]-rifamycin vs using z-scan technique. Int. Res. J. Nat. Appl. Sci. 4 (2017) 29-38.

[39] R K Fakher Alfahed, A. Imran, M.S Majeed, H. Ali Badran, Photoluminescence characterizations and nonlinear optical of PM-355 nuclear track detector film by alpha-particles and laser Irradiation, Phys. Scr. 95 (2020) 075709 (8pp).

[40] K. Abd AL-Adel, H.A. Badran, Nonlinear optical properties and diffraction ring patterns of acid black 1, Arch. Appl. Sci. Res. 4 (2012) 2499-2506.

[41] R. K. Fakher Alfahed, A. Imran, H. A. Badran, A. Al-Salihi, Synthesis, optical limiting behavior, thermal blooming and nonlinear studies of dye doped polymer films, J Mater Sci: Mater Electron, 31 (2020) 13862-13873.

[42] H. A. Badran, A.Y.AL-Ahmad, M.F.AL-Mudhaffer, C. A. Emshary, Nonlinear optical responses and limiting behavior of sulfadiazine-chromotropic acid azo dye, Opt Quant Electron,47(2015)18591867.

[43] H. A. Badran, K. I. Ajeel, H. G. Lazim, Effect of nano particle sizes on the third-order optical non linearities and nanostructure of copolymer P3HT:PCBM thin film for organic photovoltaics, Materials Research Bulletin 76 (2016) 422-430.

[44] H. A. Badran, Study on optical constants and refractive index dispersion of Neutral red doped Polymer film, American Journal of Applied Sciences 9 (2012) 250-253.

[45] H. Gazy Lazim, K. I. Ajeel, H. A. Badran, The photovoltaic efficiency of the fabrication of copolymer P3HT:PCBM on different thickness nano-anatasetitania as solar cell, Spectrochimica Acta Part A: Molecular and Biomolecular Spectroscopy 145 (2015) 598-603.

[46] N. Al-Huda S.Yakop, H. A. Badran, Single-Beam Z-Scan Measurement of the third-order optical nonlinearities of Ethidium Bromide, Int. J. of Engineering Research and Applications, 4 (2014) $727-731$

[47] H.A. Badran, A. A. Al-Fregi, R.F. Alfahed, A.S. Al-Asadi, Study of thermal lens technique and 
third-order nonlinear susceptibility of PMMA base containing 5', 5"'-dibromo-o-cresolsulfophthalein, J. of Materials Science: Materials in Electronics, 28 (2017) 17288-17296.

[48] H. A. Badran, Z-scan measurement for the thermo-optic coefficient and transmitted beam profile of 1.8-dihydroxy-naphthalin-3, 6( disulfonic acid-[2-(4-azo)]-N-5-methyl-3-isoxazolyl)-benzene sulfonamide. Adv. Phys. Theor. Appl. 26 (2013) 36- 44.

[49] P. Poornesh, S. Shettigar, G. Umesh, K.B. Manjunatha, K. Prakash Kamath, B.K. Sarojini, B. Narayana, "Nonlinear optical studies on 1,3-disubstituent chalcones doped polymer films," Optical Materials, 31 (2009) 854-859.

[50] T. Cassano, R. Tommasi, M. Ferrara, F. Babudri, G.M. Farinola, F. Naso "Subs- tituent dependence of the optical nonlinear- rities in poly (2,5-dialkoxy-p-phenylenevin- ylene) polymers investigated by the Z-scan technique, Chem. Phys., 272 (2001) 111-118.

[51] K. Abd AL-Adel, H. A. Badran, $\chi^{3}$ measurements and optical limiting in Bismarck Brown Y dye, International J. of Emerging Technologies in Computational and Applied Sciences (IJETCAS), 8 (2014) 64-68

[52] Q. Gong, Y. Sun , Z. Xia , Y. H. Zou , Z.N. Gu , X.H. Zhou, D. Qiang, Nonresonant third order optical nonlinearity of all-carbon molecules C60, J. of Applied Physics, 71 (1992) 3025.

[53] K. Abd AL-Adel, H. A. Badran, Optical nonlinear properties and optical limiting effect of congo red dye under CW Laser, Misan journal for Academic studies, 11 (2012) 1-9.

[54] H. A. Sultan, H. A. Badran, A. Y. Al-Ahmad, C. A. Emshary Experimental and theoretical study of the laser induced diffraction rings pattern in Acid Orange 10 dye : Polyacrylamide gel, Journal of Basrah Researches (Sciences) 39A (2013)1-12.

[55] R.K. Fakher Alfahed, A. S. Al-Asadi, M. F. Al-Mudhaffer, H. A. Badran, Synthesis, morphological and optical characterizations of the poly (O-toluidine)- $\mathrm{LiCl}$ networks thin film, Optics and Laser Technology 133 (2021) 106524. 
[56] R.F. Alfahed, A.S. Al-Asadi, H.A. Badran, K.I. Ajeel, Structural, morphological, and Z-scan technique for a temperature-controllable chemical reaction synthesis of zinc sulfide nanoparticles, Applied Physics B, 125 (2019) 48-58.

[57] K.M. Nashold, D.P. Walter, Investigations of optical limiting mechanisms in carbon particle suspensions and fullerene solutions, J. Opt. Soc. Am. B 12 (1995) 1228-1237.

[58] K. Mansour, M.J. Soileau, E.W. Van Stryland, Nonlinear optical properties of carbon-black suspensions (ink), J. Opt. Soc. Am. B 9 (1992) 1100-1109.

[59] V. Joudrier, P. Bourdon, F. Hache, C. Flytzanis, Characterization of nonlinear scattering in colloidal suspensions of silica particles, Appl. Phys. B 70 (2000) 105-109.

[60] S.K. Tiwari, M.P. Joshi, M. Laghate, S.C. Mehendale, Role of host liquid in optical limiting in ink suspensions, Optic Laser, Technol. 34 (2002) 487-491.

[61] A.A. Said, M. Sheik-Bahae, D.J. Hagan, T.H. Wei, J. Wang, E.W. Van Stryland, Determination of bound-electronic and free-Carrier nonlinearities in ZnSe, GaAs,CdTe, and ZnTe, J. Opt. Soc. Am. B 9 (1992) 405-414.

[62] D. Narayana Rao, Excited state dynamics in porphyrins in relevance to third-order nonlinearity and optical limiting, Opt. Mater. 21 (2002) 45-49.

[63] A.W. Allaf, M.D. Zidan, Optical limiting behavior of new fullerene derivatives, Optic Laser. Eng. 43 (2005) 57-62.

[64] P. Poornesh, Pramod K. Hegde, G. Umesh, M.G. Manjunatha, K.B. Manjunatha, A.V. Adhikari, Nonlinear optical and optical power limiting studies on a new thiophene- based conjugated polymer in solution and solid PMMA matrix, Optic Laser. Technol. 42 (2010) 230-236.

[65] B.L. Justus, A.L. Huston, A.J. Campillo, Broad band thermal optical limiter, Appl. Phys. Lett. 63 (1993) 1483-1485.

[66] G. Balaji, R.K. Rekha, A. Ramalingam, Nonlinear characterization of safranin-O dye for application 
in optical limiting, Acta Phys. Pol. 119 (2011) 359-363.

[67] M. Sheik-Bahae, A. A. Said, E.W Van Stryland, High-sensitivity single beam $n_{2}$ measurements Optics Letters 14 (1989) 955-960. 
Figures

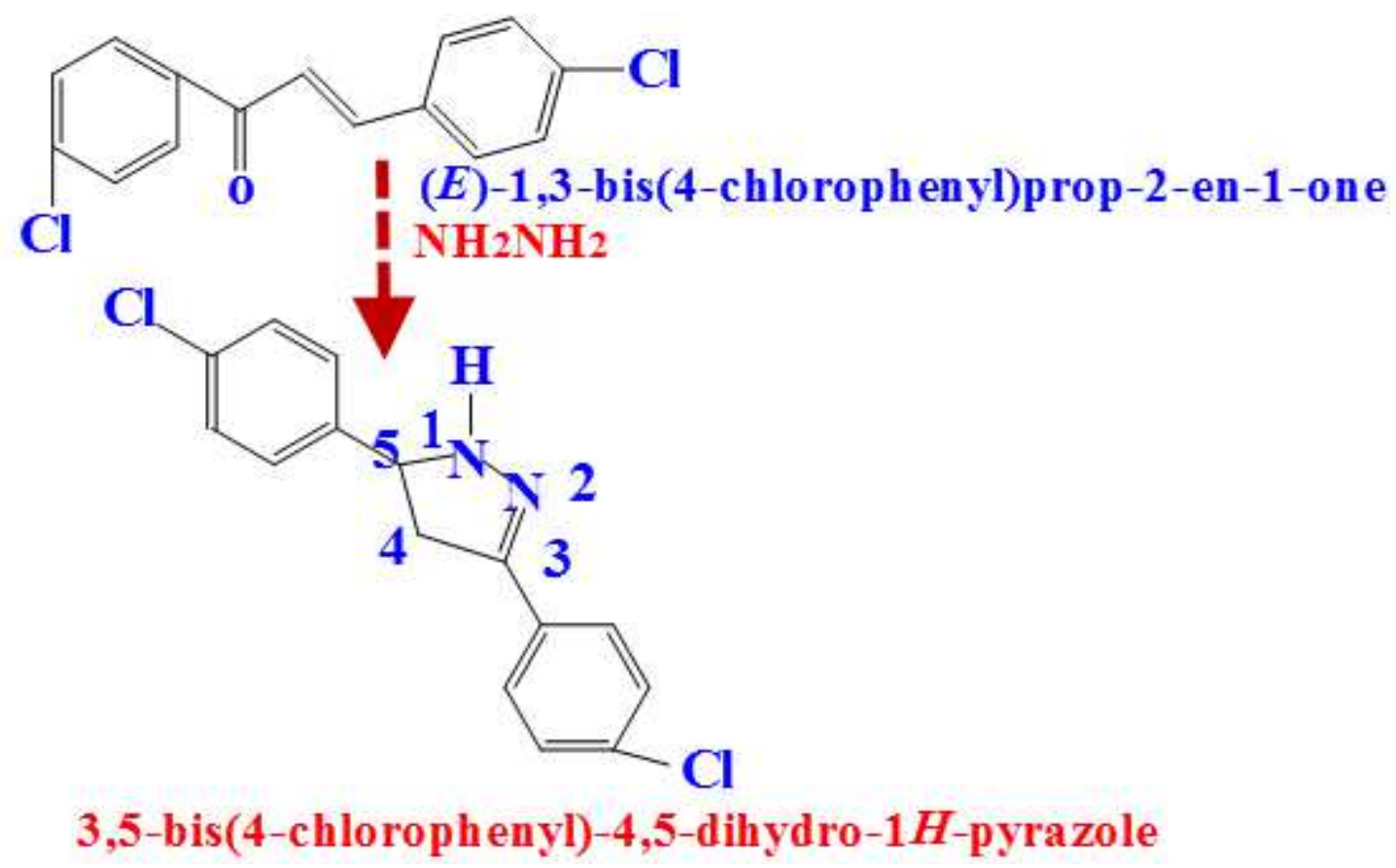

Figure 1

Schematic of new organic compound.

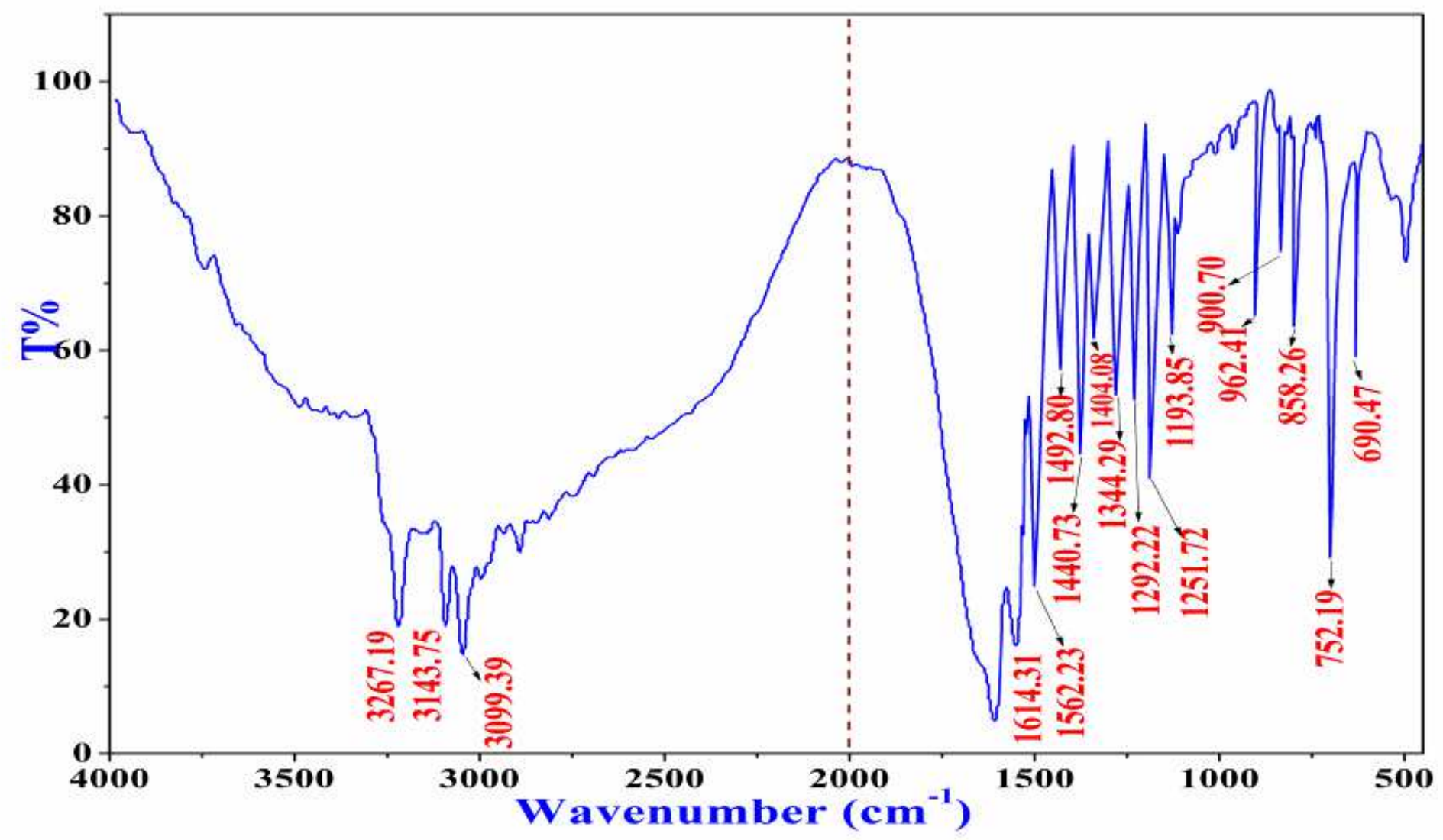


Figure 2

FT-IR spectrum of new organic compound.

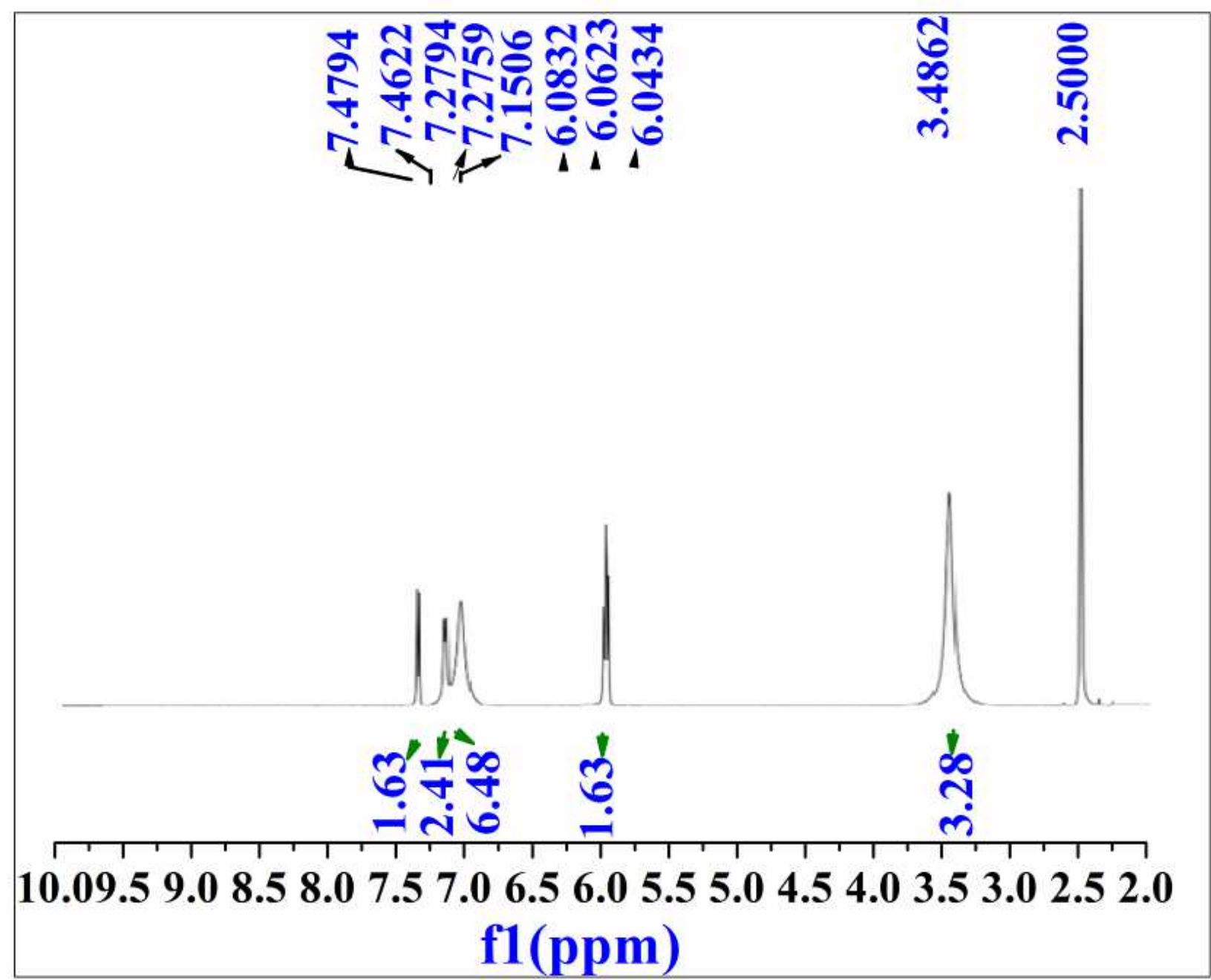

Figure 3

1HNMR spectrum of new organic compound.

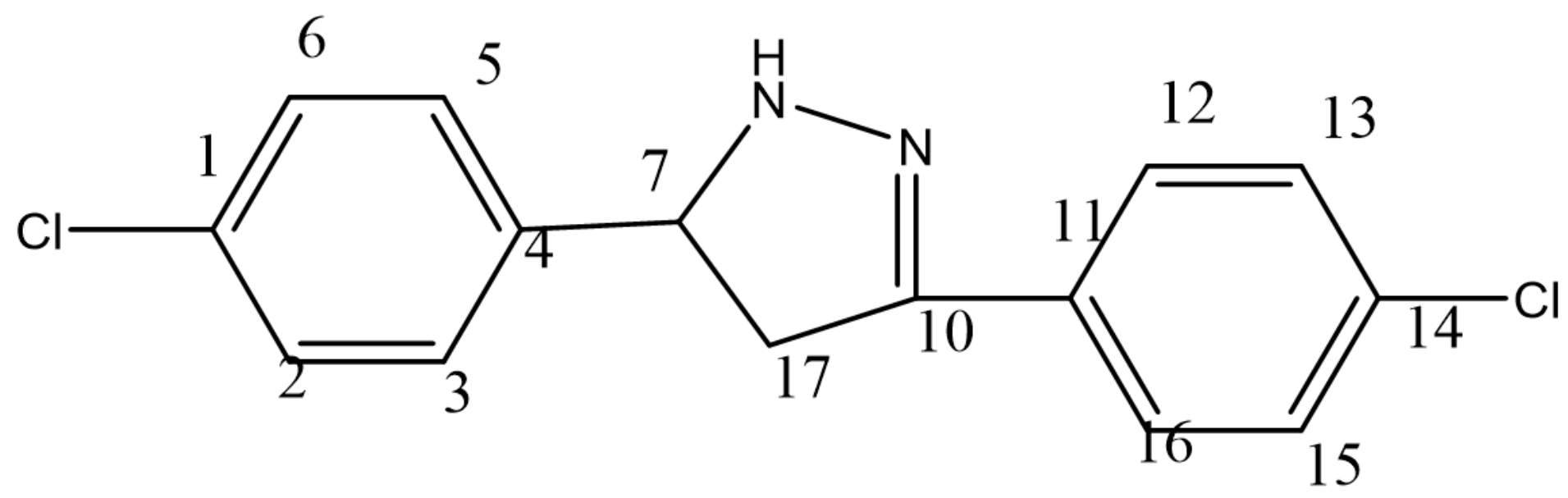


Figure 4

13CNMR Schematic of new organic compound.
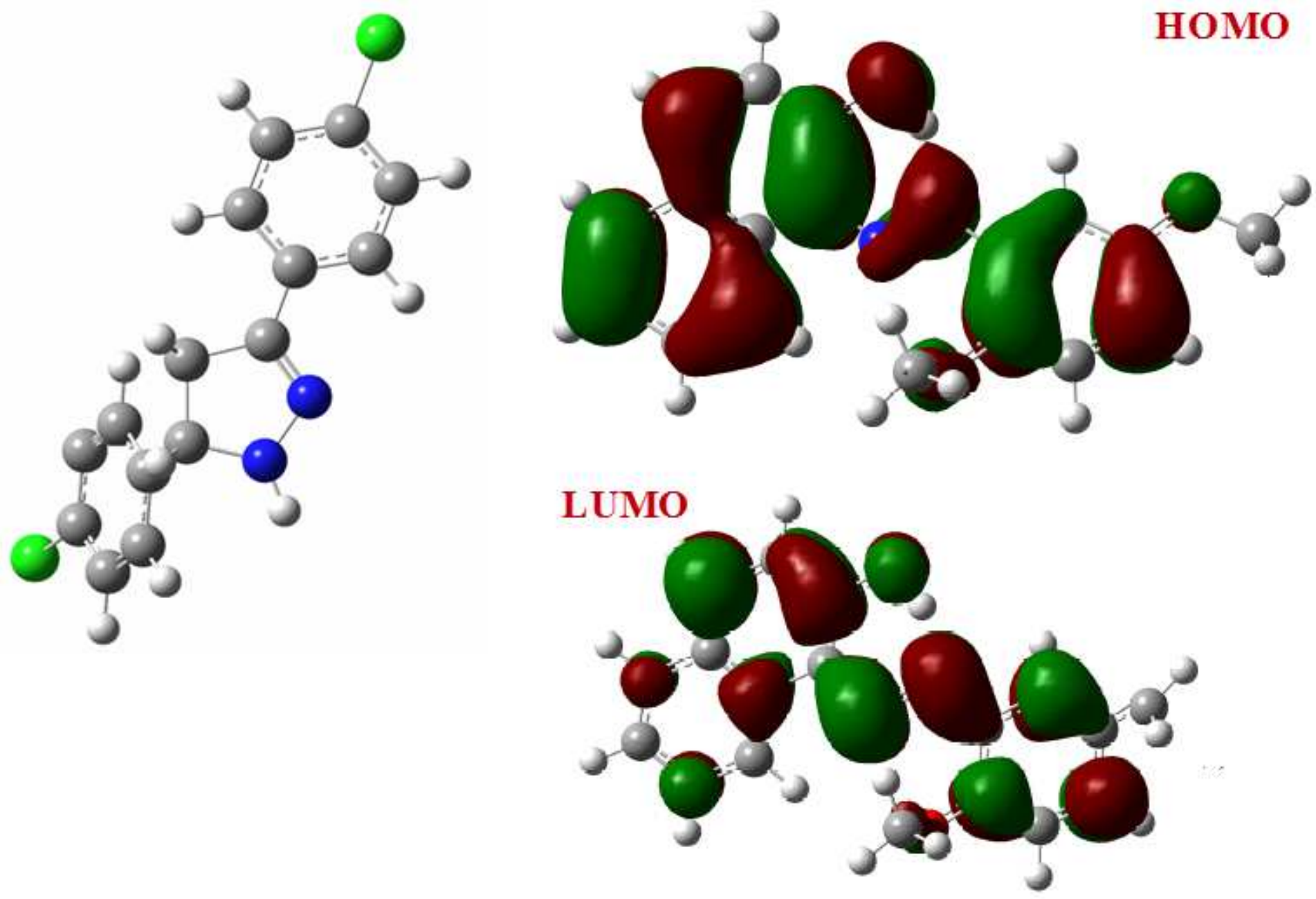

Figure 5

The optimized structure of new compound. 


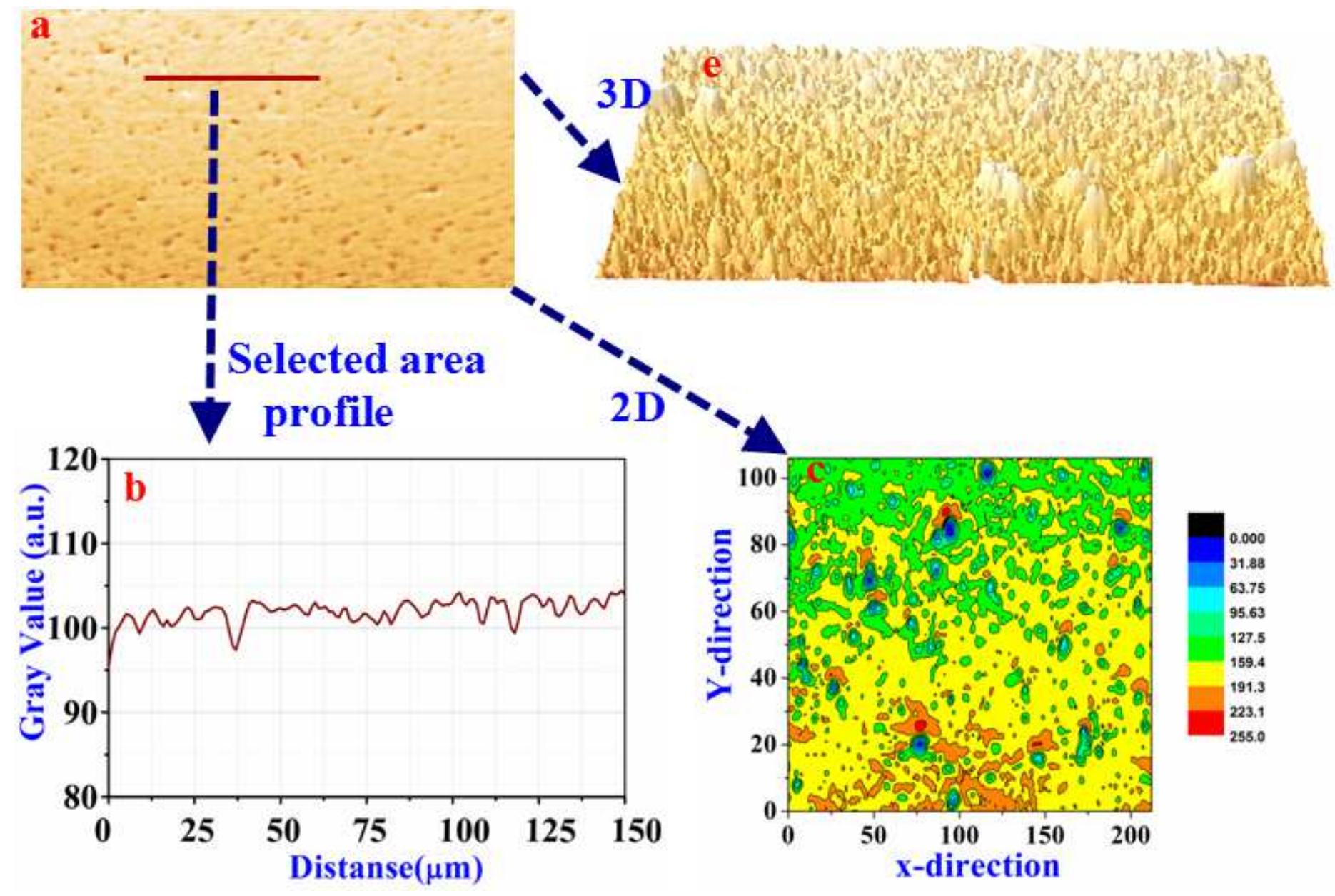

Figure 6

Photograph and Surface morphology of the POMA film. 


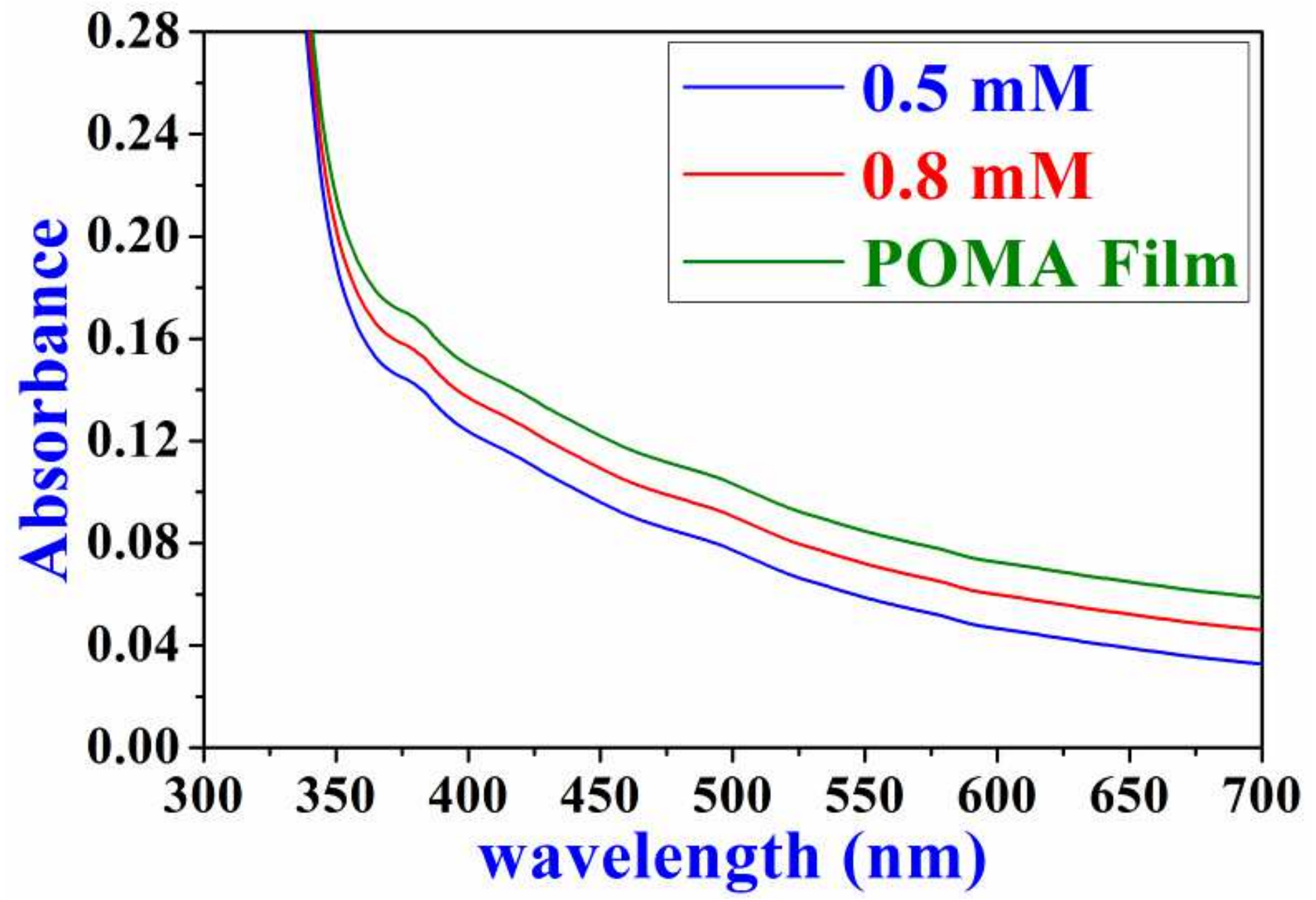

Figure 7

UV-Visible absorption spectra for POMA film and solution. 


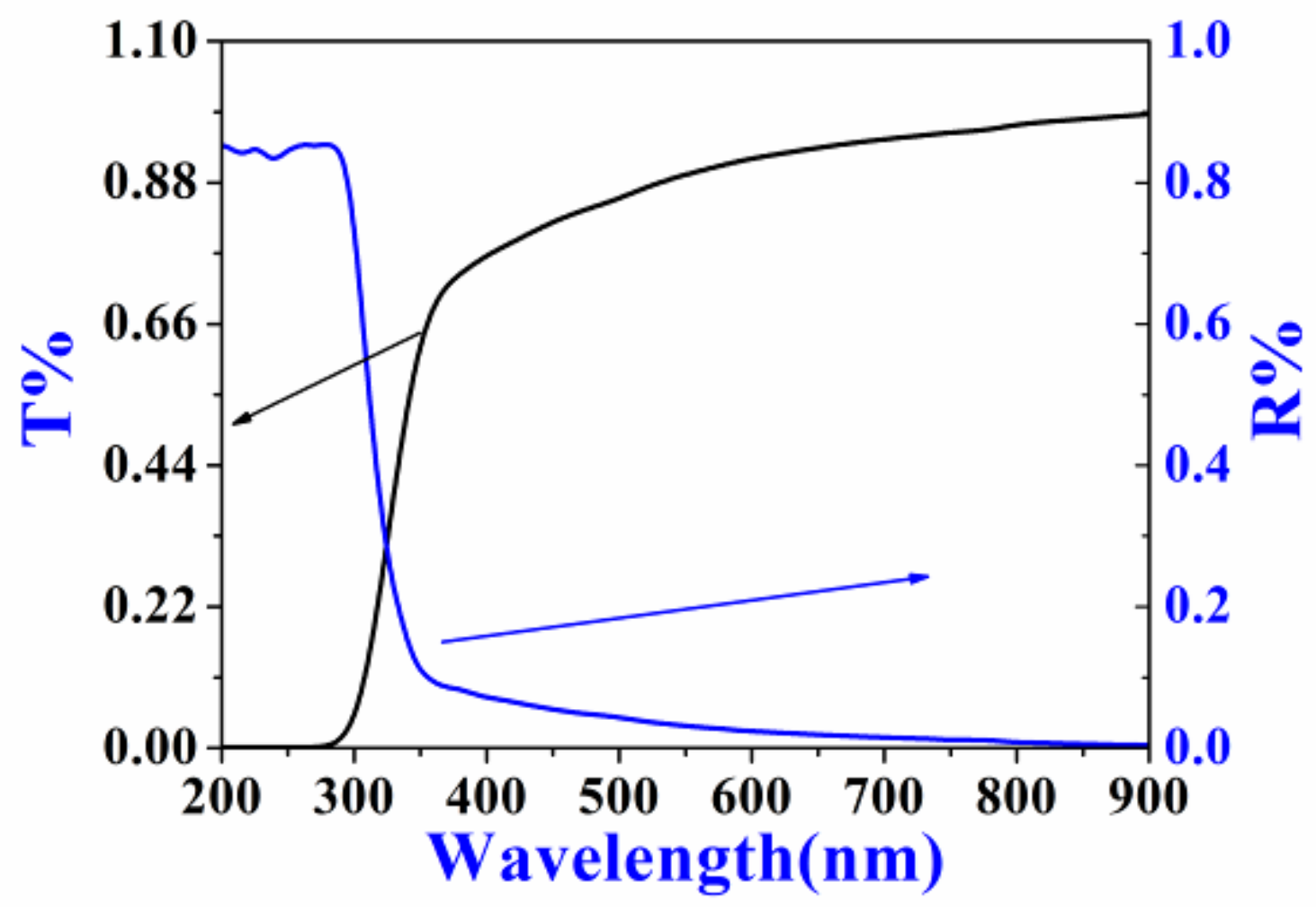

Figure 8

$T(\lambda)$ and $R(\lambda)$ Spectral of film. 


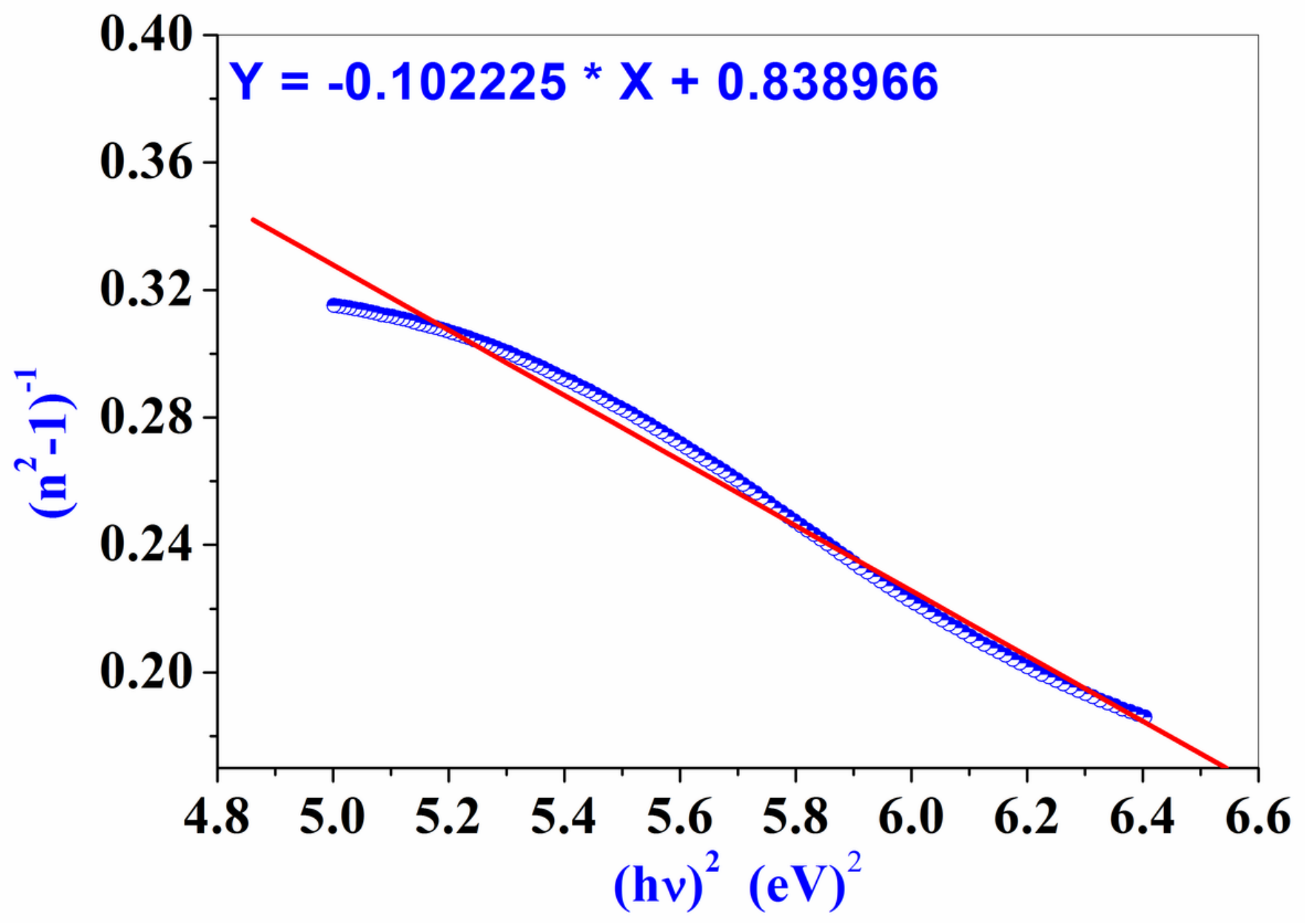

Figure 9

Plot of (n2-1)-1 vs. (hv)2 of film. 


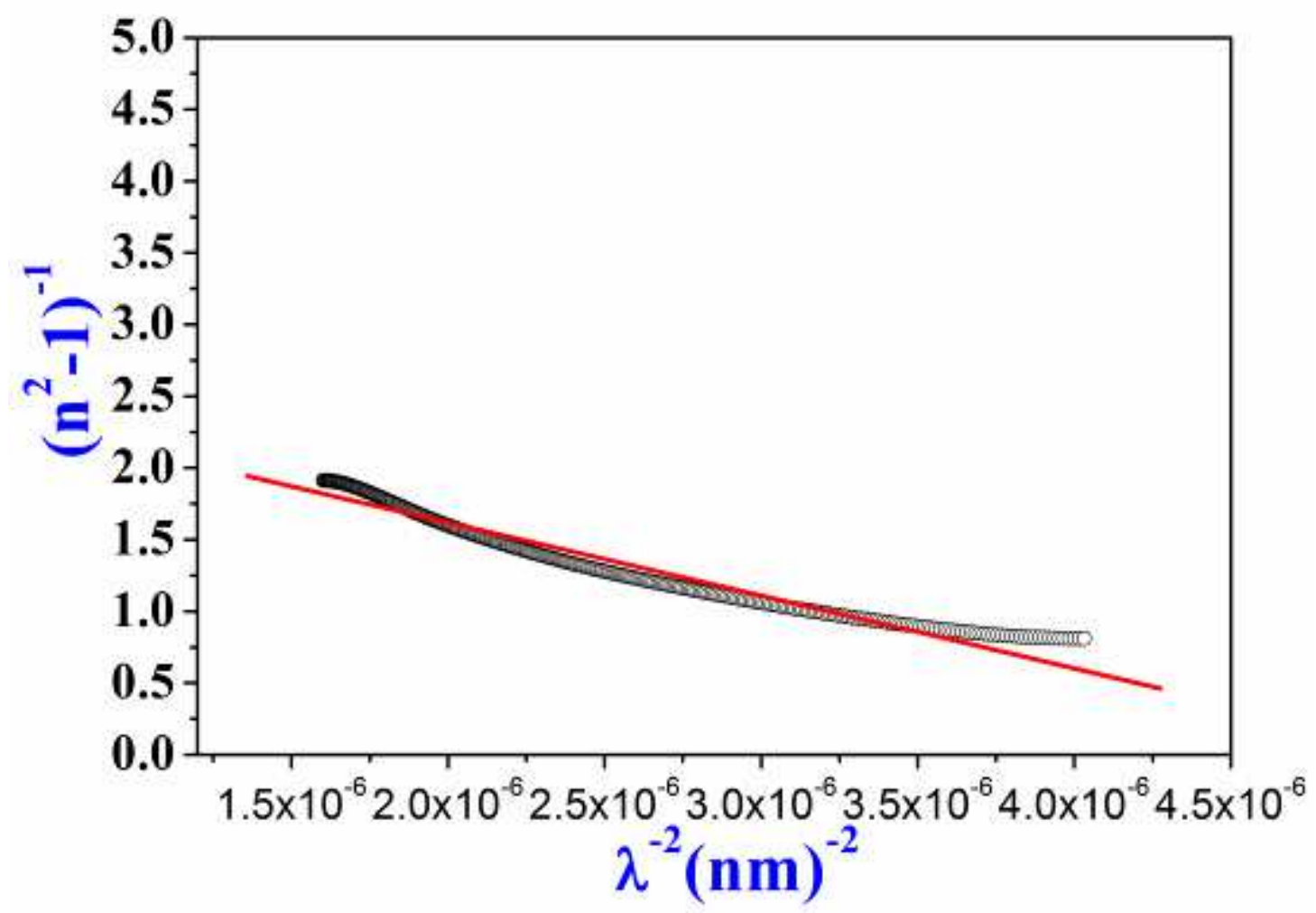

Figure 10

Plot of (n2 - 1)-1 vs. $\lambda-2$ of film.

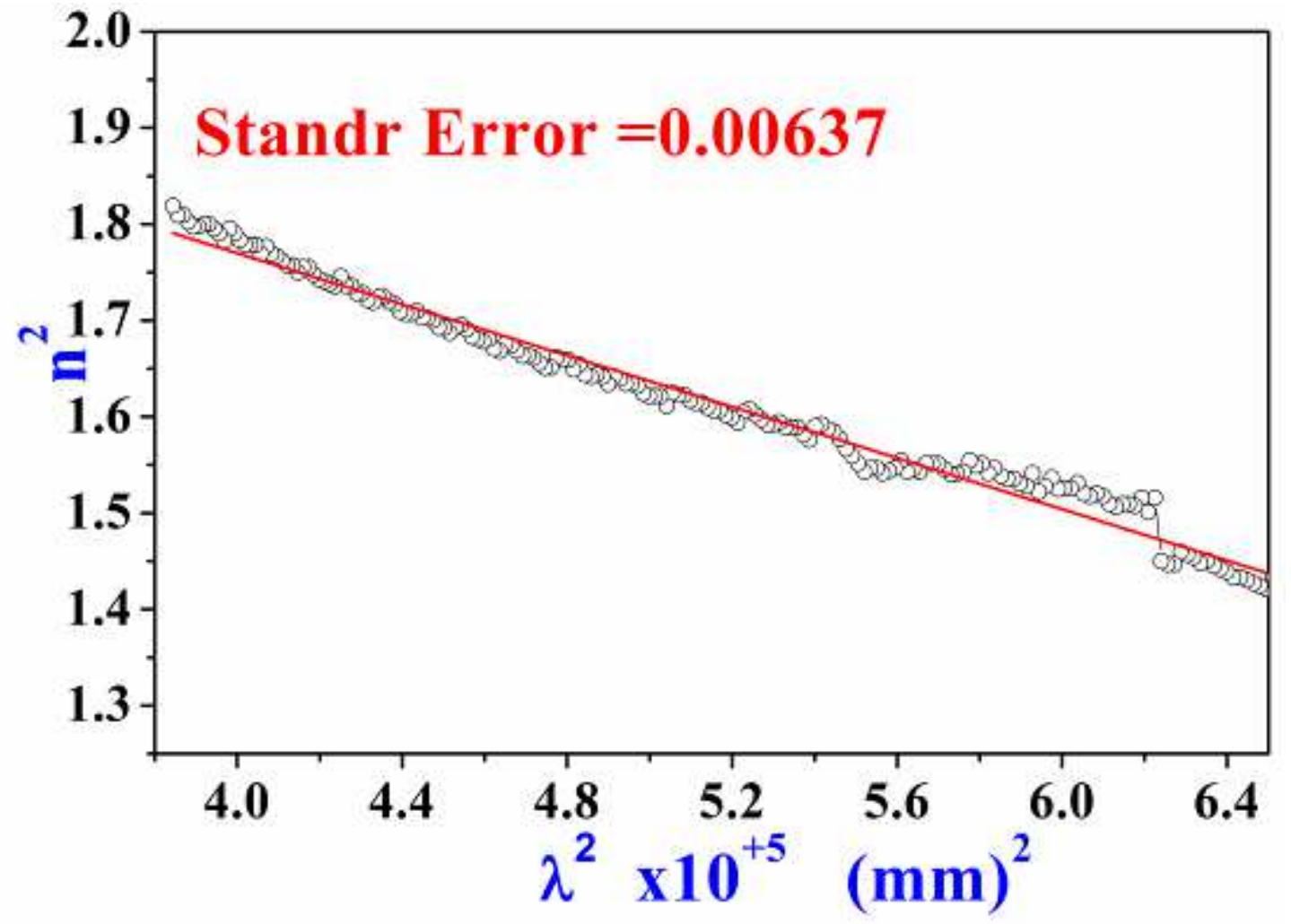

Figure 11 
Plot of n2 vs. $\lambda 2$ of film.

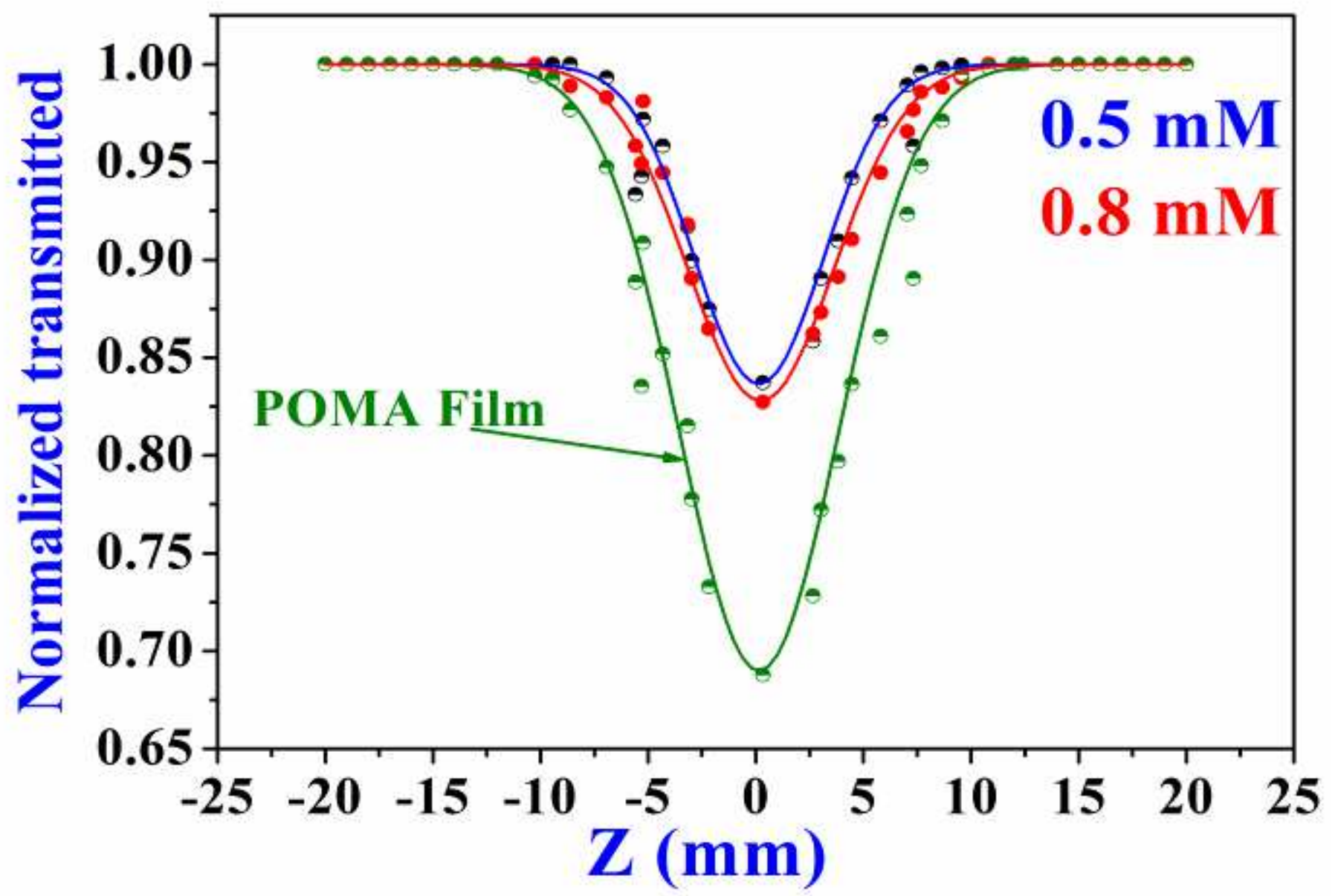

Figure 12

Open Aperture data 


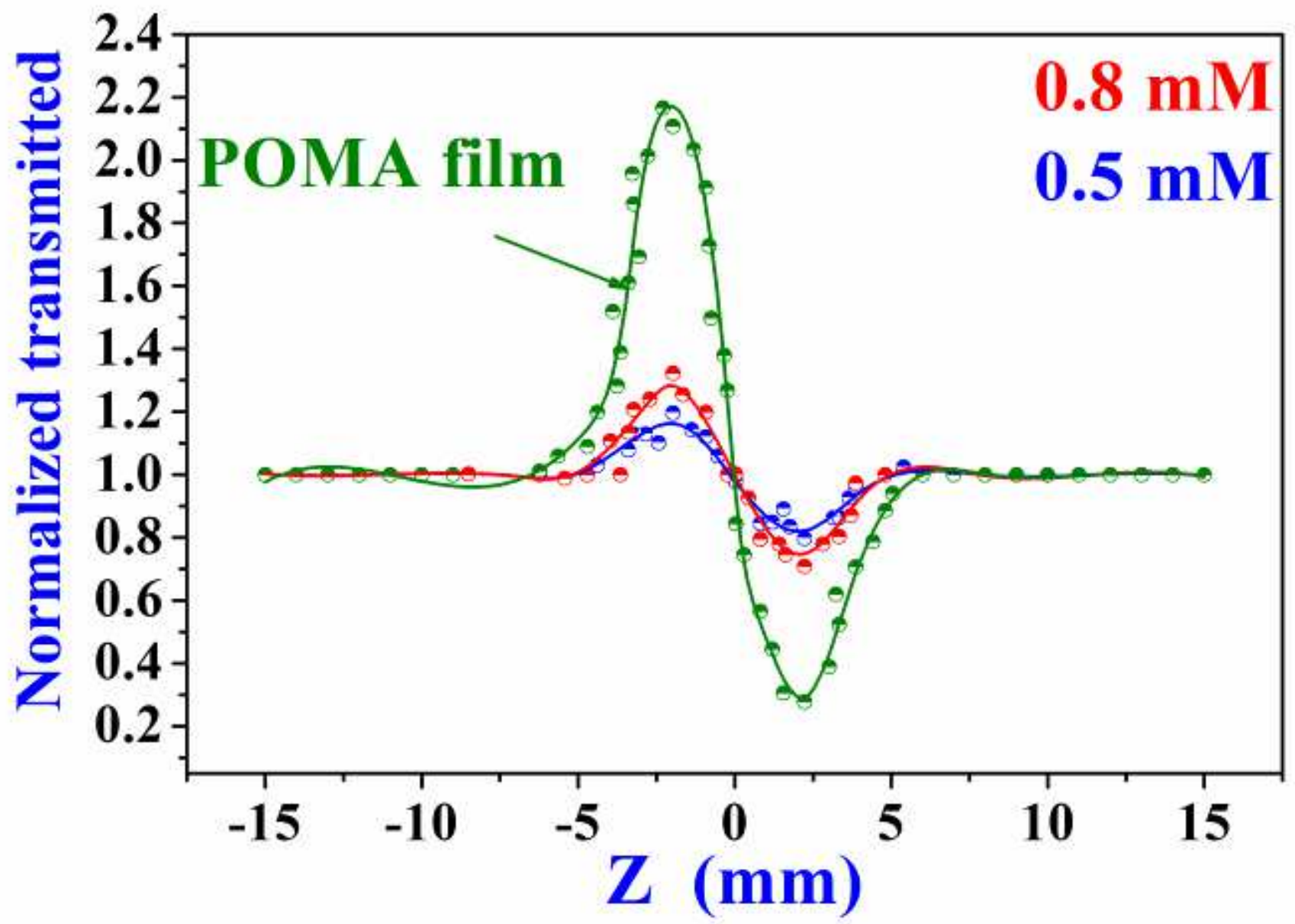

Figure 13

Pure experemental data

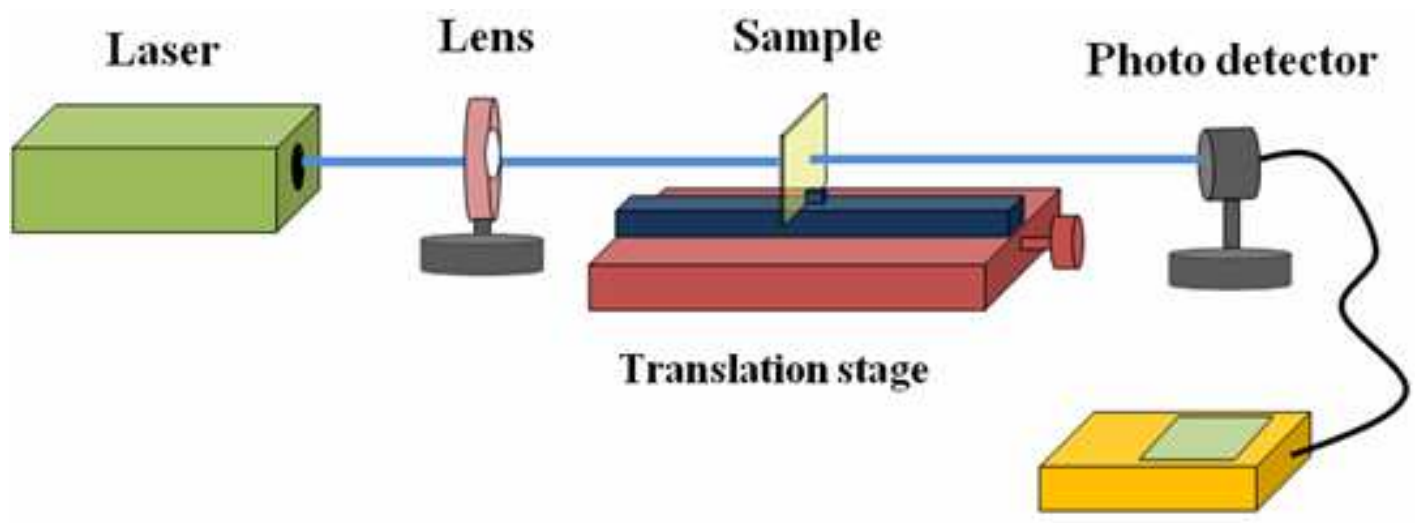

Digital power meter

Figure 14

Optical limiting experimental setup 


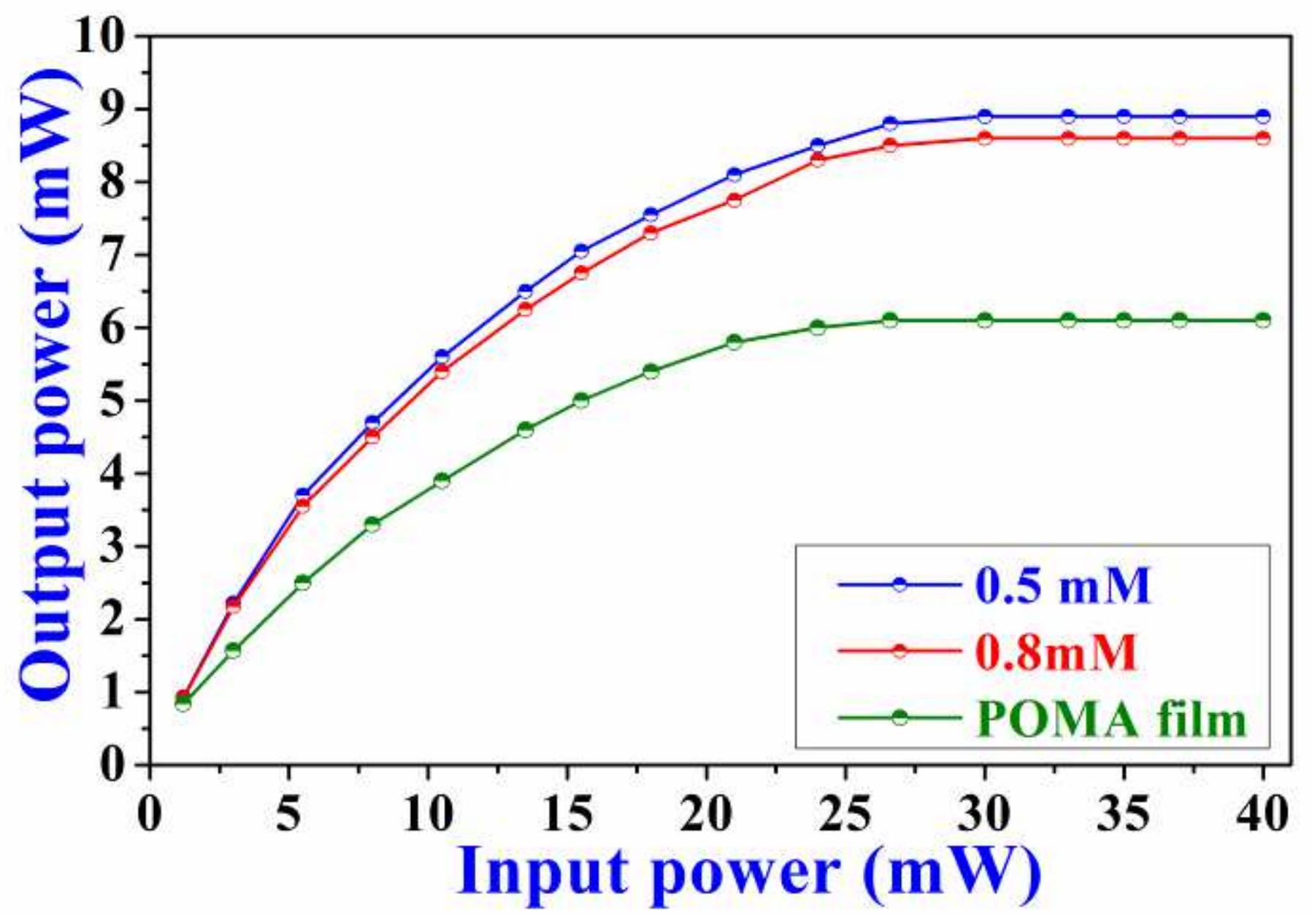

Figure 15

Optical limiting for organic compound solution and POMA film 


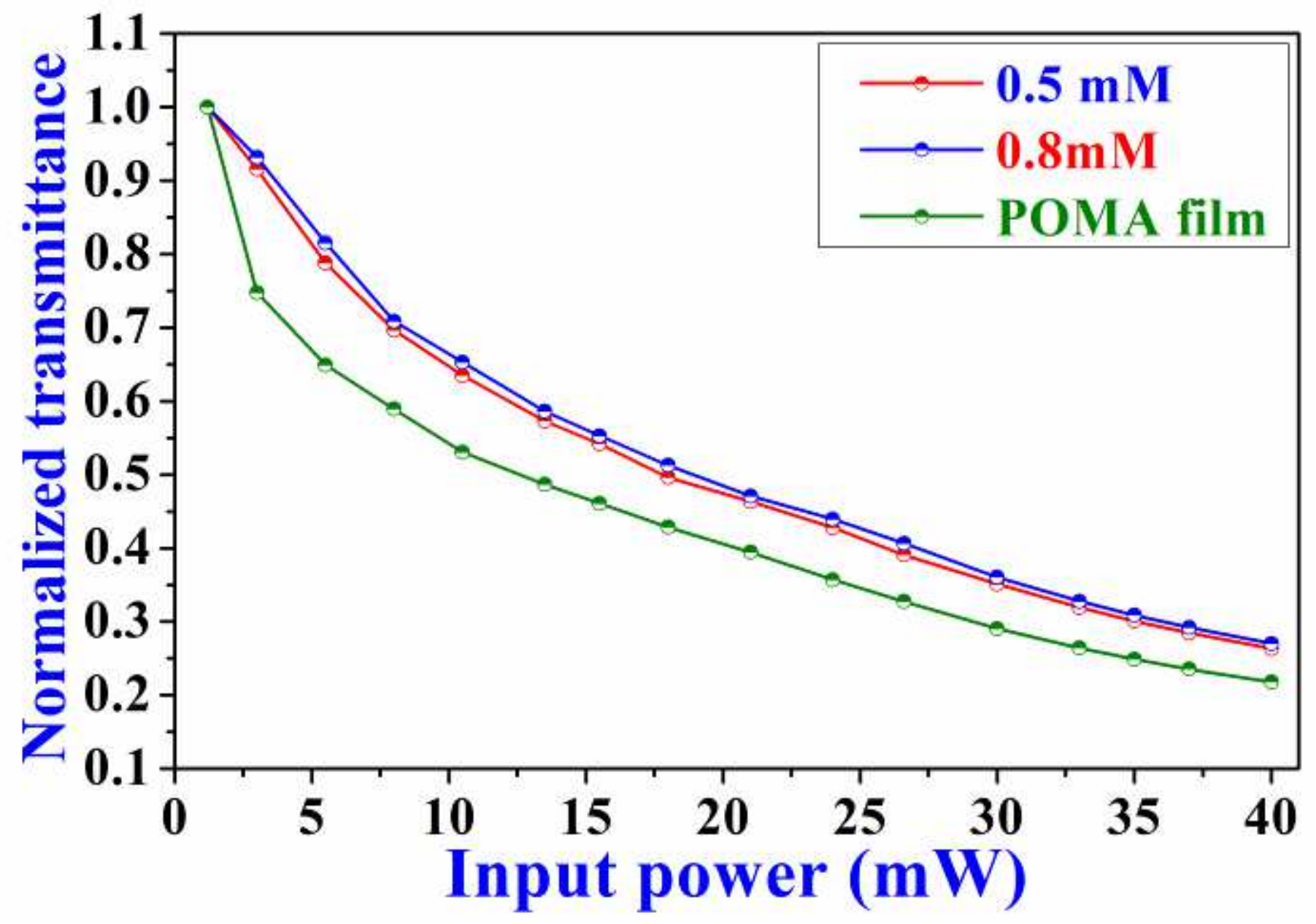

Figure 16

Normalized transmittances for organic compound solution and POMA film 